\title{
RPL3L-containing ribosomes modulate mitochondrial activity in the mammalian heart
}

\author{
Ivan Milenkovic ${ }^{1,2}$, Helaine Graziele Santos Vieira ${ }^{1}$, Morghan C Lucas ${ }^{1,2}$, Jorge \\ Ruiz-Orera ${ }^{3}$, Giannino Patone ${ }^{3}$, Scott Kesteven $^{4}$, Jianxin $\mathrm{Wu}^{4}$, Michael Feneley ${ }^{4}$, \\ Guadalupe Espadas ${ }^{1}$, Eduard Sabidó ${ }^{1}$, Norbert Hubner ${ }^{3,5,6}$, Sebastiaan van Heesch ${ }^{7}$, \\ Mirko Voelkers ${ }^{8}$ and Eva Maria Novoa ${ }^{1,2^{*}}$
}

${ }^{1}$ Centre for Genomic Regulation (CRG), The Barcelona Institute of Science and Technology, Dr. Aiguader 88, Barcelona 08003, Spain

${ }^{2}$ Universitat Pompeu Fabra (UPF), Barcelona, Spain

${ }^{3}$ Cardiovascular and Metabolic Sciences, Max Delbrück Center for Molecular Medicine in the Helmholtz Association (MDC), Berlin 13125, Germany

${ }^{4}$ Victor Chang Cardiac Research Institute, Darlinghurst NSW 2010, Australia.

${ }^{5}$ Charité -Universitätsmedizin, 10117 Berlin, Germany

${ }^{6}$ German Centre for Cardiovascular Research (DZHK), Partner Site Berlin, 13347 Berlin, Germany

${ }^{7}$ Princess Máxima Center for Pediatric Oncology, Heidelberglaan 25, 3584 CS, Utrecht, the Netherlands.

${ }^{8}$ University of Heidelberg, Heidelberg, Germany.

* Correspondence to: Eva Maria Novoa (eva.novoa@crg.eu) 


\section{ABSTRACT}

The existence of naturally occurring ribosome heterogeneity is now a well-acknowledged phenomenon. However, whether this heterogeneity leads to functionally diverse 'specialized ribosomes' is still a controversial topic. Here, we explore the biological function of RPL3L, a ribosomal protein (RP) paralog of RPL3 that is exclusively expressed in muscle and heart tissues, by generating a viable homozygous $R p / 3 /$ knockout mouse strain. We identify a rescue mechanism in which, upon Rp/3I depletion, RPL3 becomes upregulated, yielding RPL3-containing ribosomes instead of RPL3L-containing ribosomes that are typically found in cardiomyocytes. Using both ribosome profiling (Ribo-Seq) and a novel orthogonal approach consisting of ribosome pulldown coupled to nanopore sequencing (Nano-TRAP), we find that RPL3L neither modulated translational efficiency nor ribosome affinity towards a specific subset of transcripts. By contrast, we show that depletion of RPL3L leads to increased ribosome-mitochondria interactions in cardiomyocytes, which is accompanied by a significant increase in ATP levels, potentially as a result of mitochondrial activity fine-tuning. Our results demonstrate that the existence of tissue-specific RP paralogs does not necessarily lead to enhanced translation of specific transcripts or modulation of translational output. Instead, we reveal a complex cellular scenario in which RPL3L modulates the expression of RPL3, which in turn affects ribosomal subcellular localization and, ultimately, mitochondrial activity. 


\section{INTRODUCTION}

A major challenge in biology is to comprehend how protein synthesis is regulated with surgical precision, both in the spatial and the temporal context. While many layers of gene expression regulation have been extensively studied over the years, ribosomes have been historically perceived as static and passive elements that do not partake in regulatory processes. Several works, however, have challenged this view [1-5], and have provided evidence that ribosomes with specialized functions exist, and can preferentially translate specific subsets of mRNAs [6]. While naturally occurring ribosome heterogeneity is now a well-documented phenomenon [7-9], whether this heterogeneity leads to functionally diverse 'specialized ribosomes' is still a controversial topic [10-13].

Ribosomes are supramolecular ribonucleoprotein complexes responsible for protein synthesis in all known organisms. Eukaryotic ribosomes consist of two subunits: the small $40 \mathrm{~S}$ subunit, which is made up of 32 ribosomal proteins (RPs) and the $18 \mathrm{~S}$ ribosomal RNA (rRNA), and the large 60S subunit, comprised of $47 \mathrm{RPs}$ and the 5S, 5.8S and 28S rRNA [14]. While the structure and composition of ribosomes was thought to be largely invariant [15], several studies that examined in further detail the dynamics of RP composition and their relationship with ribosome function suggest the contrary $[2,6,8,10,16-18]$. For example, ribosomal protein stoichiometry in yeast and mouse stem cells was shown to depend on the number of ribosomes bound per mRNA [8]. Similarly, RPL38 was shown to be of paramount importance for the translation of Homeobox mRNAs in mice [2], while RPL10A-containing ribosomes were found to preferentially translate a subpool of mRNAs in mouse stem cells [6].

Eukaryotes contain many duplicated genes encoding RPs, which for a long time were thought to be functionally redundant $[19,20]$. However, a pioneering study in yeast revealed that depletion of RP paralogs does not lead to the same phenotypes, suggesting paralog-specific functions [3]. In mammals, RP paralogs have been shown to be differentially expressed upon tumorigenesis [9] and some of them are exclusively expressed in restricted subsets of tissues [9]. For example, $R p / 3$ is constitutively expressed in all tissues, whereas the expression of its paralog gene, $R p / 3 /$, is restricted to heart and skeletal muscle tissues [21]. Thus, while the existence of heterogeneous ribosomes in terms of RP composition is well documented [22,23], the biological function of RP paralog genes with restricted tissue-specific expression, such as $R p / 3 l$, is largely unknown.

The human RPL3L gene was first identified in studies focusing on autosomal dominant polycystic kidney disease gene regions, in which the authors identified a gene sharing $77 \%$ identity with the mammalian $R p / 3$ gene $[24,25]$. These studies found that $R P L 3 L$ was exclusively expressed in heart and skeletal muscle, but no further indications were found as to its role in these tissues [25]. Two decades later, it was found that RPL3L is downregulated upon hypertrophic stimuli, and it was 
proposed that RPL3L may function as a negative regulator of muscle growth [14]. In support of this hypothesis, mutations in the human Rp/3/ gene have been linked to several heart disorders, including atrial fibrillation [26,27] and childhood-onset cardiomyopathy [28]. However, why certain tissues express distinct RP proteins, and with what biological relevance, still remains unclear.

Here, we used a combination of wet lab and bioinformatics techniques to study the role of the RPL3-RPL3L pair in protein translation in the mouse heart. We found that $R p / 3 /$ is expressed only postnatally, with its expression limited to specific cell types, in addition to being restricted to heart and muscle tissues. Specifically, we observed that in hearts, Rp/3l was exclusively expressed in cardiomyocytes, whereas $R p / 3$ was mainly expressed in non-myocyte heart cell types. To explore the biological function of $R p / 3$, we generated a viable homozygous $R p / 3 /^{--}$mouse strain, where we identified a rescue mechanism in which RPL3 becomes upregulated upon Rp/3/ knockout, yielding RPL3-containing ribosomes instead of RPL3L-containing ribosomes that are typically found in mouse cardiomyocytes. Using both ribosome profiling (Ribo-seq) and ribosome pulldown coupled to nanopore sequencing (Nano-TRAP), we identified only a handful of differentially translated transcripts

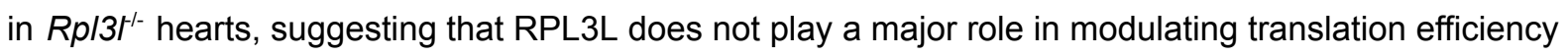
or ribosome affinity towards preferentially translating a specific subset of transcripts. By contrast, when coupling ribosome pulldown to proteomics (Proteo-TRAP), we found that a very large amount of mitochondrial proteins were significantly enriched in RPL3-containing ribosome immunoprecipitates in cardiomyocytes. We then confirmed that RPL3, unlike RPL3L, is detected in the mitochondrial fraction of heart lysates, suggesting that the use of either of the two paralogs might be fine-tuning the ribosome-mitochondria interactions in cardiomyocytes. Moreover, we show that ATP levels, but not mitochondrial abundance, are significantly increased in $R p / 3 /^{--}$cardiomyocytes.

Altogether, our work reveals that upon depletion of Rp/3l, RPL3 is upregulated, mimicking the RPL3/RPL3L interplay that occurs upon hypertrophic stimuli [14]. This switch in RPL3/RPL3L expression patterns causes RPL3 to replace RPL3L in cardiac or skeletal muscle ribosomes, which in turn leads to higher proportion of ribosome-bound mitochondria and consequently increased ATP production.

\section{RESULTS}

\section{RPL3L is a vertebrate-specific RP paralog that is expressed postnatally in cardiomyocytes}

Previous works have shown that RP paralogs are not equally expressed across mammalian tissues [9]. However, their expression patterns across developmental stages have been much less studied. Here, we examined the dynamics of RP paralog expression patterns across both tissues and developmental stages using publicly available RNA-seq datasets [29]), which included 7 major organs (brain, cerebellum, heart, kidney, liver, ovary, testis) from embryos (E10.5 to E18.5) and postnatal 
bioRxiv preprint doi: https://doi.org/10.1101/2021.12.04.471171; this version posted December 4,2021 . The copyright holder for this preprint (which was not certified by peer review) is the author/funder, who has granted bioRxiv a license to display the preprint in perpetuity. It is made available under aCC-BY-NC-ND 4.0 International license.

mice (P0, P3, P14, P28, P63). We found that most RPs were constitutively expressed in all tissues, in agreement with previous observations, and found that these RPs typically showed relatively stable expression levels across developmental stages (Figure 1A, see also Figure S1). By contrast, the expression patterns of RP paralogs fell into one of three possible behaviors: i) one of the two paralogs is expressed in all tissues, while the other is only expressed postnatally in a single tissue (e.g., Rp/3-Rp/3I, Rp/10-Rp/10I, Rp/39-Rp/39I); ii) both paralogs are expressed in similar levels across tissues and developmental stages (e.g., Rp/22-Rp/22/1) or iii) one of the paralogs is dominantly expressed across tissues and developmental stages, while the other one is either expressed at lower levels or not expressed at all (e.g., Rp/7-Rp/7I1, Rp/36a-Rp/36al, Rps27-Rps27I) (Figure 1B).
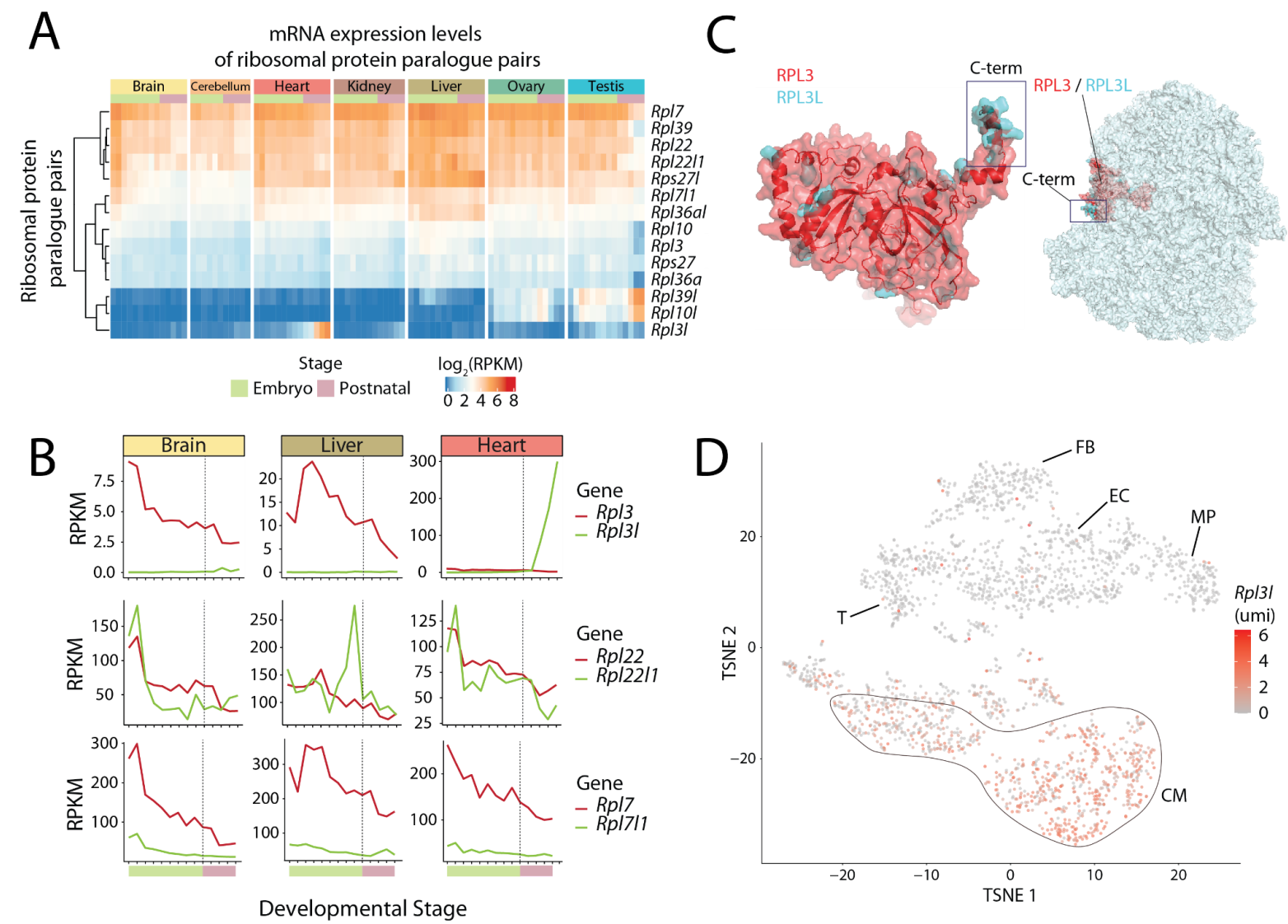

Figure 1. RPL3L is a vertebrate RP paralog with restricted tissue and developmental expression patterns, such as postnatal expression in mouse cardiomyocytes. (A) Heatmap of mRNA expression levels (log RPKM) of ribosomal proteins and their respective paralogs across embryonic (green: E10.5, E11.5, E12.5, E13.5, E14.5, E15.5, E16.5, E17.5, E18.5) and postnatal mice tissues (pink: P0, P3, P14, P28, P63). Processed data (RPKM) was obtained from Cardoso-Moreira et al. [29]. See also Figure S1 for heatmap containing all ribosomal proteins. (B) mRNA expression levels of ribosomal paralog pairs (RPKM) in 3 different tissues (brain, liver and heart) for $R p / 3 / R p / 3 /$ (upper panel), Rp/22/Rp/22/1 (middle panel) and Rp/7 and Rp/7/1 (bottom panel). The developmental stages, shown on the x-axis, have been colored depending on whether they correspond to embryonic (green) or postnatal (pink) stages. (C) Structural alignment of human RPL3 (red) and RPL3L (cyan), the C-terminus is highlighted (left) and location of RPL3/RPL3L within the ribosome (right). The ribosome structure has been obtained from the cryo-EM structure of the human $80 S$ ribosome, corresponding to PDB code 6IP5 [30], which includes RPL3. The $H$. sapiens RPL3L structure was obtained from the ModBase [31] database and structurally superimposed to the RPL3 structure in the $80 S$ ribosome. (D) T-distributed stochastic neighbor embedding (T-SNE) plot depicting Rpl3I expression across mouse heart cell types. Expression data has been extracted from publicly available single-cell RNAseq data from Ren et al. [32]. Each dot represents a cell. Abbreviations: CM (cardiomyocytes), EC (endothelial cells), FB (fibroblasts), MP (macrophage), T (T cells). 
We observed that RP paralog genes (Rp/3l, Rp/10l and Rp/39/) that displayed tissue-specific expression patterns also followed similar temporal expression patterns across developmental stages, in which their expression levels increased steeply from embryo to postnatal developmental stages. Moreover, in those tissues where the tissue-specific RP paralog was expressed, the expression levels of their counterparts (Rp/3, Rp/10 and Rp/39) decreased postnatally, coinciding with increased expression levels of their paralog (Figure 1A), suggesting a possible regulatory interplay between RP paralog pairs.

The $R p / 3 /$ paralog gene emerged in early vertebrates (Figure S2A), and its sequence is relatively similar to that of its paralog gene Rp/3 (75\% sequence identity), with the C-terminus being the most distinct region between the two paralogs (Figure S2B). A superimposition of the RPL3L homology model in the ribosome structure shows that the differential C-terminal region is located on the surface of the ribosome (Figure 1C), suggesting that RPL3L-containing ribosomes could potentially alter the ability of certain accessory proteins to bind to the ribosome, in a similar fashion to what has been previously observed with RPL36 and RPS17-containing ribosomes [33].

To examine with further detail the expression patterns of $R p / 3 /$, we used publicly available single-cell RNA-seq data from mouse hearts [32], revealing that the expression of $R p / 3 /$ in heart tissues is in fact restricted to cardiomyocyte (CM) cells (Figure 1D). Thus, Rp/3/ expression is not only restricted to specific developmental stages and tissues, but also, its expression is limited to myocyte cell types.

\section{Rp/3I knockout mice show upregulated RPL3 expression in heart and muscle and decreased lean body mass}

To reveal the biological function of $R p / 3 l$, we generated constitutive knockout mouse models for both $R p / 3$ and Rp/3/ using the CRISPR-Cas9 system (Figure 2A, see also Figure S3). Depletion of Rp/3I in mice led to viable homozygous knockout mice $\left(R p / 3 \digamma^{-}\right)$, with offspring following mendelian proportions. Knockout of $R p / 3 /$ was validated both at the mRNA level (Figure 2B) as well as at the protein level (Figure 2C,D, see also Figure S4 and S5). By contrast, depletion of Rp/3 led to an embryonic-lethal phenotype, and only heterozygous knockout mice $\left(R p / 3^{+/}\right)$could be obtained (see Methods).

Histopathological analysis of heart and skeletal muscle tissues (gastrocnemius and quadriceps) from $R p / 3 T^{--}$mice did not reveal pathological traits nor significant morphological changes compared to control $\mathrm{Rpl}_{3 \mathrm{I}^{+/+}}$mice (Figure 2E, see also Figure S6A and Methods). No statistically significant differences were found between $R p / 3 H^{--}$and WT mice in heart weight, muscle weight, heart-body weight ratio nor in heart-brain weight ratio (Figure S6B, see also Table S1). The left and right ventricular free wall thickness was also found to be non-significant, albeit with a moderate but not significant increase in $R p / 3 r^{\prime}$ left ventricular free wall thickness $(p=0.0615)$. At the physiological level, 
bioRxiv preprint doi: https://doi.org/10.1101/2021.12.04.471171; this version posted December 4,2021 . The copyright holder for this preprint (which was not certified by peer review) is the author/funder, who has granted bioRxiv a license to display the preprint in perpetuity. It is made available under aCC-BY-NC-ND 4.0 International license.

echocardiographic profiles of $R p / 3 r^{--}$mice showed no significant differences to those of control $R p \mid 3 \mathrm{I}^{+/+}$ mice (Figure S7, see also Table S2). However, EchoMRI ${ }^{\mathrm{TM}}$ analysis of body composition of live mice showed a significant increase in total lean mass in aged $R p / 3 r^{-}$knockout mice when compared to age-matched WT mice ( $n=5$ vs 5 ; $p$-value $=0.02$ ), but not in younger 8 week old mice ( $n=5$ vs 5 ; p-value $=0.47)($ Figure 2F, see also Figure S6C and Methods).
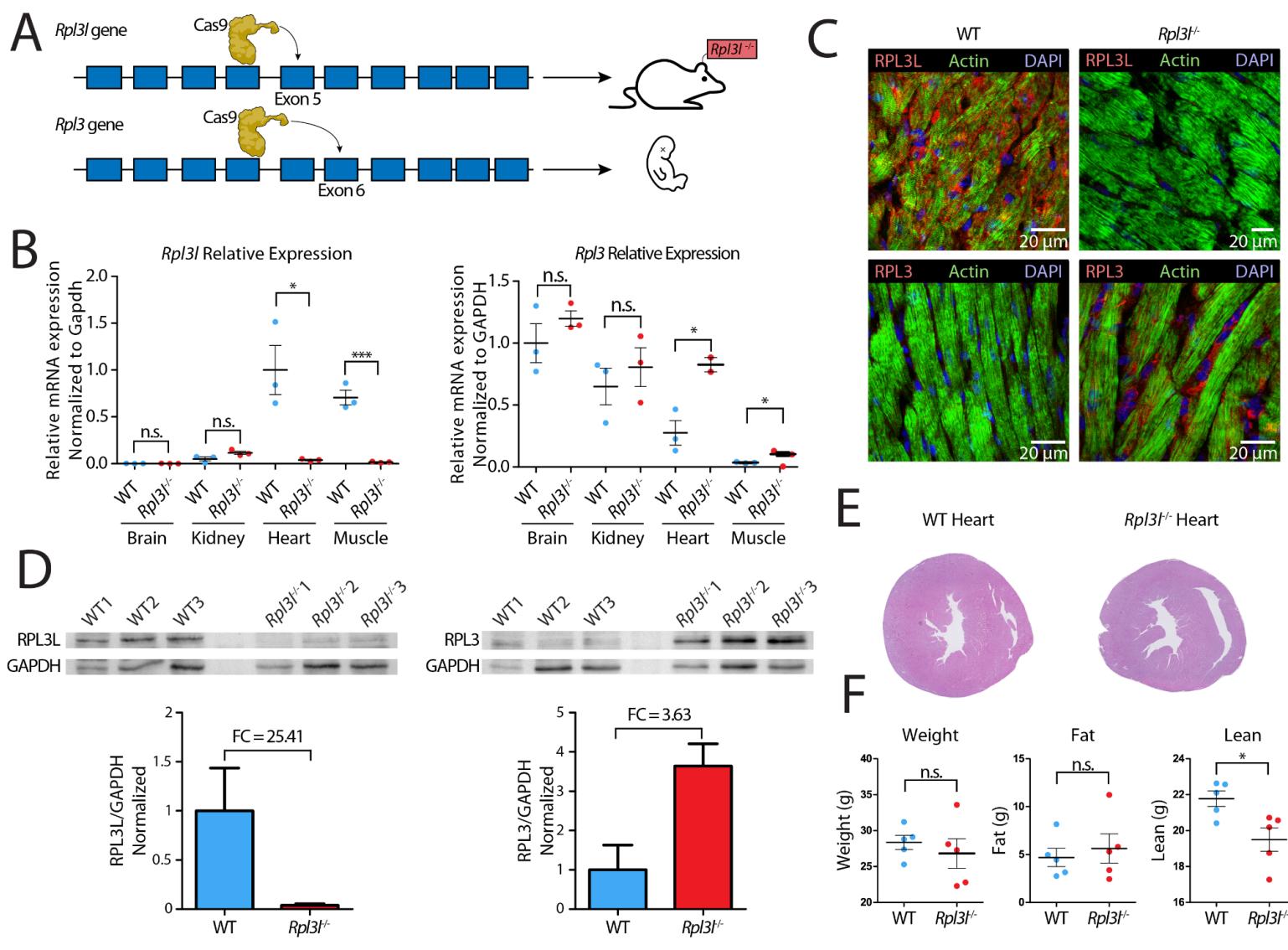

\section{$\mathrm{E}$}
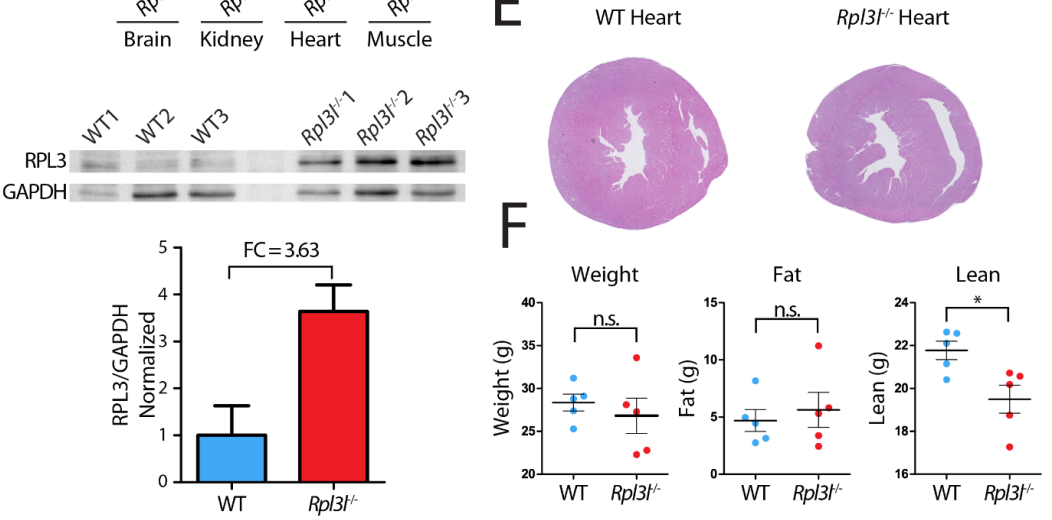

Figure 2. Phenotypic and molecular characterization of $R p / 3 r^{-1-}$ knockout mice. (A) Strategy for $R p / 3^{-1-}$ and $R p / 3 H^{--}$mice generation using the CRISPR-Cas9 system. $R p / 3 H^{--}$mice were successfully generated by introducing a 13-bp deletion in exon 5. Rpl3 $3^{--}$mice have an embryonic lethal phenotype. See also Figure S3. (B) Relative expression levels of $R p / 3 /$ (left) and Rp/3 (right) measured using RT-qPCR and normalized to Gapdh. Rp/3 is ubiquitously expressed, while $R p / 3 /$ is heart- and muscle-specific. $R p / 3 r^{-1}$ mice do not express $R p / 3 /$ in any of the tissues $(n=3)$. Statistical significance was assessed using the unpaired t-test ${ }^{*}$ for $p<0.05$, ${ }^{* *}$ for $p<0.01$, ${ }^{* * *}$ for $p<0.001$ ). (C) Immunofluorescence staining of RPL3 and RPL3L in both WT (left) and $R p / 3 H^{/-}$mice heart tissues (right). Nuclei have been stained with DAPI and are shown in blue, actin is depicted in green and RPL3L (top) and RPL3 (bottom) in red. (D) Western blot analysis of RPL3L (left) and RPL3 (right) in cardiomyocytes isolated from WT and $R p / 3 H^{--}$hearts $(n=3)$. In the bottom, barplots depicting the fold change of Rpl3 and Rpl3I expression in cardiomyocytes is shown. RPL3L and RPL3 levels were normalized to GAPDH. See also Figure S4 for full blot images, and Figure S5 for western blot results using total heart samples from WT and $R p / 3 r^{/-}$mice. (E) Representative histological sections of WT and $R p / 3 T^{--}$heart tissues stained with hematoxylin and eosin. A total of 10 mice were included in the histological analyses. See also Figure S6. (F) EchoMRI analyses of aged WT and $R p / 3 H^{--}$mice, in which weight, fat and lean mass were measured for each animal $(n=5)$. Statistical significance was assessed using unpaired t-test ( ${ }^{*}$ for $\left.p<0.05\right)$.

At the molecular level, we observed that depletion of $R p / 3 /$ led to a significant increase in $R p / 3$ expression levels in heart and skeletal muscle, both at the mRNA (Figure 2B) and protein level 
bioRxiv preprint doi: https://doi.org/10.1101/2021.12.04.471171; this version posted December 4, 2021. The copyright holder for this preprint (which was not certified by peer review) is the author/funder, who has granted bioRxiv a license to display the preprint in perpetuity. It is made available under aCC-BY-NC-ND 4.0 International license.

(Figure 2C,D). Thus, a compensatory mechanism upon the absence of Rpl3l seems to be present in cardiomyocytes, leading to the production of RPL3-containing ribosomes in cardiomyocytes, a cell type where RPL3-containing ribosomes are normally not present postnatally. This biological compensation provides a biological setup that allows for a functional comparative study of the ribosomal activity of RP paralogs in cardiomyocytes, i.e., by comparing the translational activity of cardiomyocytes with RPL3L-containing ribosomes (in wild type mice) or RPL3-containing ribosomes (in $R p / 3 \digamma^{\prime-}$ mice), respectively.

\section{RPL3L and RPL3 are incorporated into translating ribosomes}

RPL3 is a highly conserved core ribosomal protein, and it is well-documented that the incorporation of RPL3 into ribosomes is of paramount importance for their function [34] (Figure 1D). Even though RPL3L has been described as a tissue-specific paralog of RPL3, whether it is actually incorporated into translating ribosomes remains elusive.

A WT heart
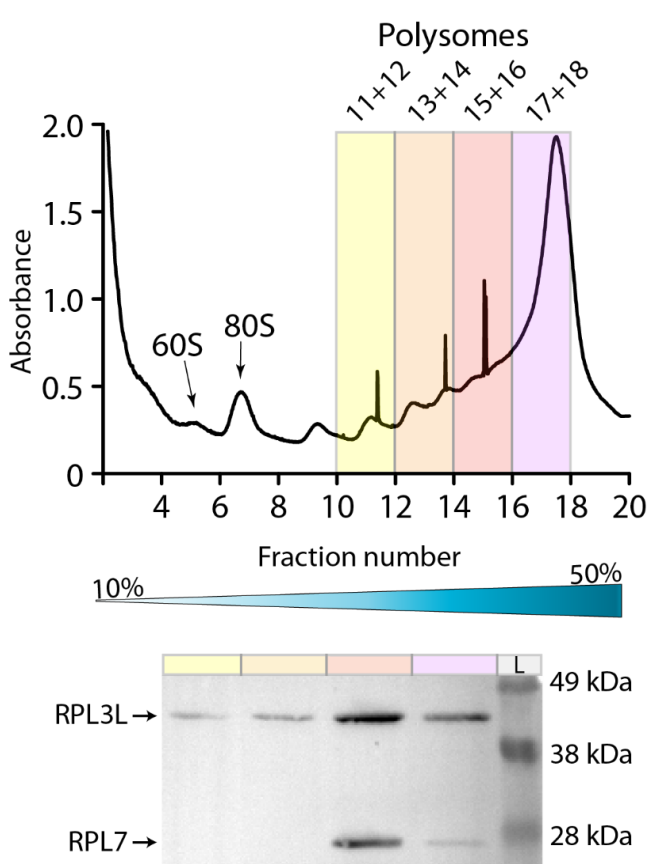

B

$R p / 3 H^{-1-}$ heart
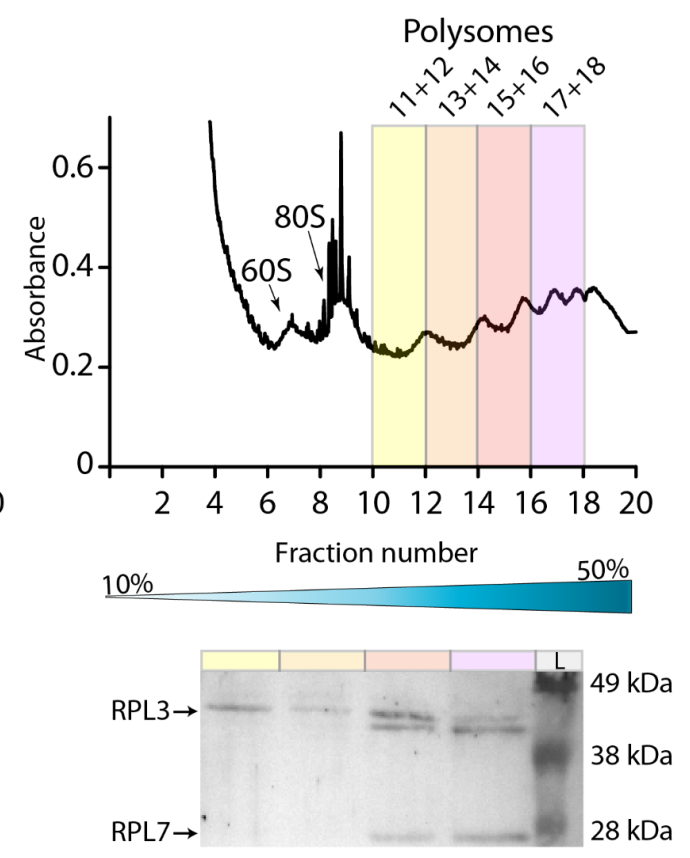

Figure 3. RPL3L and RPL3 are incorporated into translating ribosomes in WT and Rp/3I $^{- \text {- }}$ hearts, respectively. Polysome profiles of (A) WT heart and (B) $R p / 3 \digamma^{--}$heart done in $10-50 \%$ sucrose gradients with corresponding western blot analyses. The membranes were probed with anti-RPL3L, anti-RPL3 and anti-RPL7 antibodies to show the incorporation of both paralogs in translating ribosomes. See also Figure S8 for biological replicates and uncropped gel images.

To examine the incorporation of RPL3L and RPL3 into translating ribosomes in WT and $R p / 3 r^{- \text {- }}$ cardiomyocytes, respectively, we performed sucrose gradient fractionation of polysome extracts from WT and $R p / 3 r^{--}$mice hearts (Figure 3). Polysome fractions were collapsed, protein content was 
extracted and subsequently analysed using western blot, and probed with anti-RPL3L and anti-RPL3 antibodies. Our results showed that RPL3L is found in the polysome fractions, demonstrating that RPL3L was incorporated into translating ribosomes (Figure 3A). Moreover, we observed that upon Rp/3/ depletion, RPL3L compensated for the missing paralog by replacing it in the $60 \mathrm{~S}$ subunit, and was incorporated into translating ribosomes from $R p / 3 /^{--}$mice (Figure 3B). Finally, we noted that $R p / 3 /$ depletion led to decreased absorbance in high-polysome fractions, suggesting that translation is partially impaired in RPL3-containing cardiomyocyte ribosomes that are found in $R p / 3 r^{--}$mice.

\section{The use of RPL3L does not lead to preferential translation or enhancement of translation efficiency}

Previous works have shown that heterogeneity in RP composition endows ribosomes with differential selectivity for translating subpools of transcripts including those controlling metabolism, cell cycle, and development [6]. Specifically, it was found that RPL10A and RPS25-bearing ribosomes showed preferential translation of subsets of transcripts when compared to the whole ribosome population. However, it is unclear whether the use of RP paralogs would lead to preferential translation of specific subsets of transcripts.

Here we examined this question by testing whether RPL3L-containing ribosomes showed preferential translation of subsets of transcripts, relative to RPL3-containing ribosomes. To this end, we devised a novel method, which we termed Nano-TRAP: HA-tag mediated Translating Ribosome Affinity Purification (TRAP) [35] coupled to nanopore cDNA sequencing (Figure 4A, see also Methods). Nano-TRAP captures full-length mRNAs that are associated with at least one 80 s ribosome. We applied Nano-TRAP in biological triplicates to mouse hearts that were isolated from either $R p / 22-\mathrm{HA}^{+/+} / R p / 3 H^{--}$or control $R p / 22-\mathrm{HA}^{+/+} / R p / 3 I^{+/+}$hearts corresponding to mRNA populations that are bound to RPL3- and RPL3L-containing ribosomes, respectively. We first examined the replicability of Nano-TRAP, finding that per-gene log2-counts across biological replicates were highly replicable (pearson $r^{2}=0.886-0.939$ ) (Figure S9A,B). We then performed differential expression (DE) analysis to examine whether the ribosome-bound mRNA populations would be significantly distinct upon knock-out of $R p / 3 /$, finding only 5 differentially-bound transcripts (Figure 4B, see also Table S3). Our results identified $R p / 3$ as one of the differentially-bound mRNAs, in agreement with our previous results that showed upregulation of $R p / 3$ upon $R p / 3 /$ depletion (Figure $2 \mathrm{~B}$ ). In addition to increased binding to Rp/3 transcripts, RPL3L-depleted ribosomes showed significantly decreased binding towards 2 genes including Ankrd1, a transcription factor whose dysregulation has been associated with several types of cardiomyopathies $[36,37]$ including hypertrophic cardiomyopathy.

Finally, we examined whether translation efficiency (TE) would be significantly altered upon Rp/3/ depletion. TE was calculated by dividing normalized counts from the IP experiment by those from the input experiment. We then compared TE results between WT and $R p / 3 r^{--}$strains (Figure 4C), 
however, we did not observe a significant change in TE of specific transcripts. Altogether, our analyses using Nano-TRAP suggest that the use of RPL3L instead of RPL3 in translating ribosomes does not globally lead to preferential translation of subsets of transcripts in mouse hearts.

\section{$R p / 3 /$ depletion does not affect the distribution of ribosomes along transcripts}

It has been reported that RPL3, which is located close to the peptidyl-transferase centre in the ribosome, plays a role in preventing ribosomes from piling up in the mRNA 5' region early during translation elongation [34]. Therefore, we wondered whether the presence of RPL3 or RPL3L in ribosomes might lead to changes in the distribution of ribosomes along specific transcripts.

To examine this, we performed ribosome profiling (Ribo-Seq) [38] in WT and $R p / 3 r^{- \text {- }}$ mouse hearts (Figure 4D, see also Figure S10), in biological triplicates, finding a consistent 3-nucleotide periodicity in ribosome-protected (RPF) libraries in all samples (Figure S11A). We first examined whether the depletion of $R p / 3 /$ led to accumulation of reads in specific genic regions. To this end, we analyzed the distribution of reads of ribosome-protected footprints (RPFs) at the metagene level; however, we did not observe statistically significant differences between WT and Rp/3r- RPF reads, finding that reads mapped in similar proportions to the 3' UTR, CDS and 5' UTR (Figure 4E). Similarly, metagene analyses showed that RPFs did not accumulate in specific regions of the transcript (Figure 4F, see also Figure S12).

We then assessed whether Ribo-Seq, when integrated with RNA-seq, would be able to identify transcripts with differential mRNA expression levels (input mRNA), ribosomal occupancy (RFP), or translational efficiency (TE). This revealed that Rp/3/ depletion did not globally lead to changes in

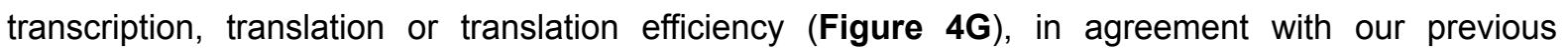
observations using Nano-TRAP. Finally, we examined whether RPL3 and RPL3L-containing ribosomes would show differences in ribosome codon occupancies; however, we did not find significant differences between WT and $R p / 3 \digamma^{- \text {- }}$ hearts (Figure 4H, see also Figure S11B). 
bioRxiv preprint doi: https://doi.org/10.1101/2021.12.04.471171; this version posted December 4, 2021. The copyright holder for this preprint (which was not certified by peer review) is the author/funder, who has granted bioRxiv a license to display the preprint in perpetuity. It is made available under aCC-BY-NC-ND 4.0 International license.

\section{A Nano-TRAP}

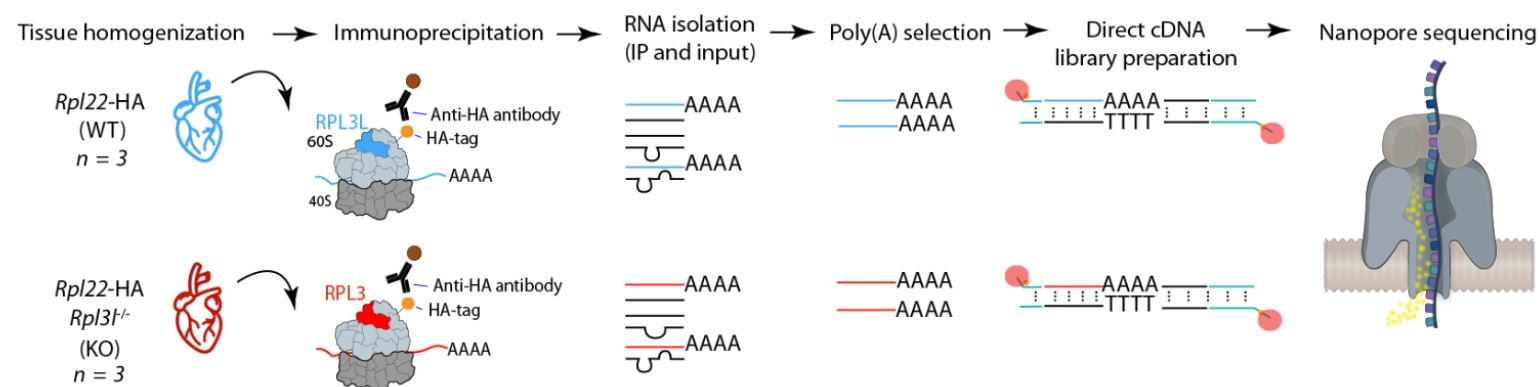

B

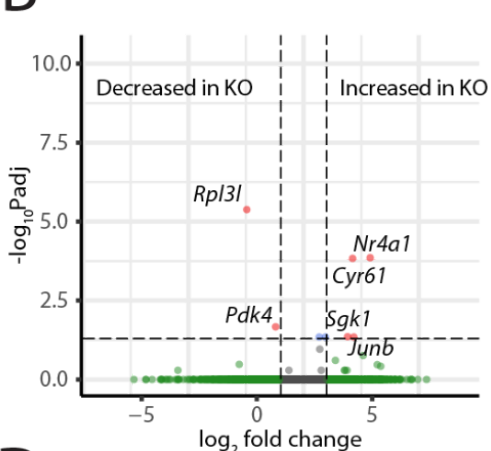

$\log _{2}$ fold change

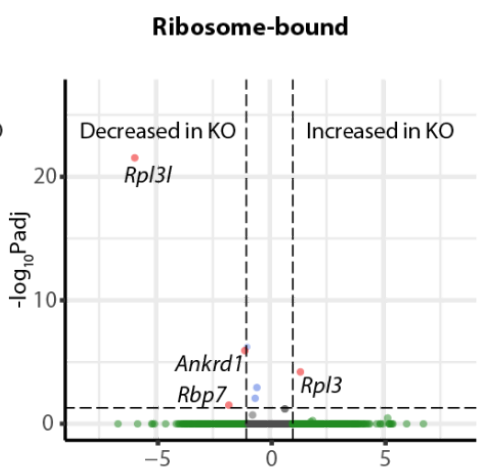

$\log _{2}$ fold change

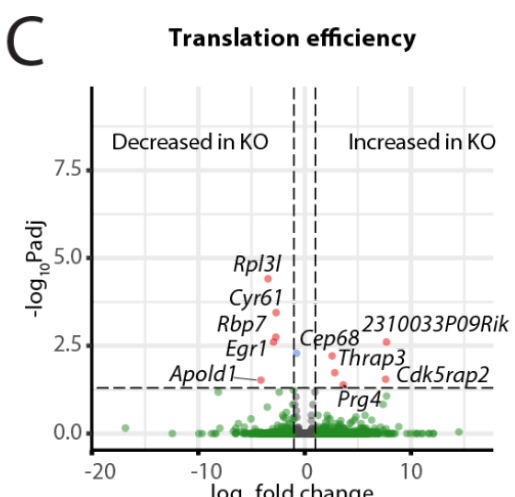

$\log _{2}$ fold change

\section{Ribo-Seq}

Tissue homogenization $\rightarrow$ Polysome extraction $\rightarrow$ RNA digestion $\rightarrow$ RPF purification $\rightarrow \begin{aligned} & \text { Library preparation } \\ & \text { (total RNA and RPFs) }\end{aligned} \rightarrow$ Illumina sequencing

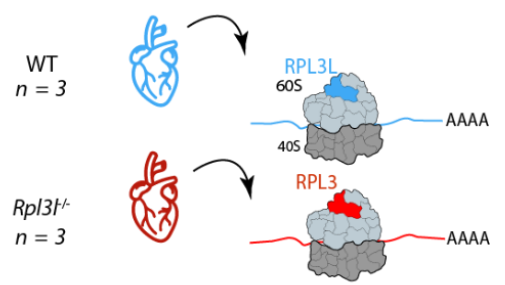

E

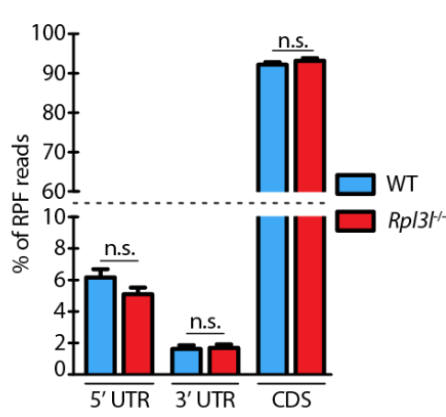

$\mathrm{H}$

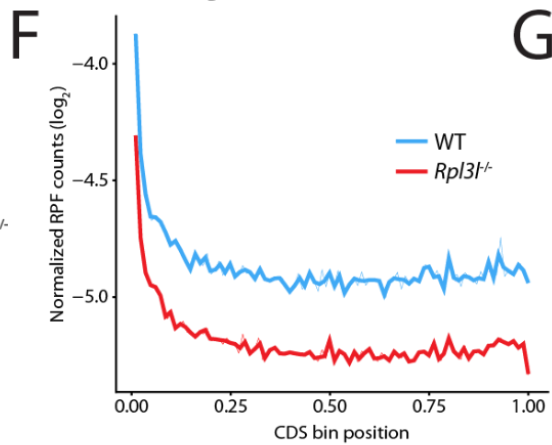

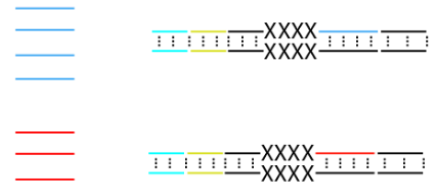

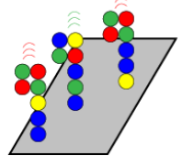

G

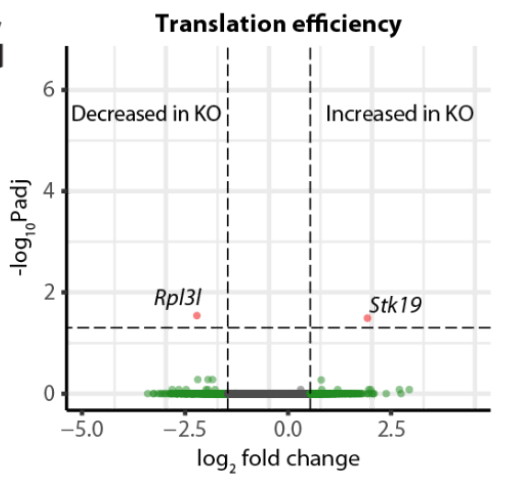

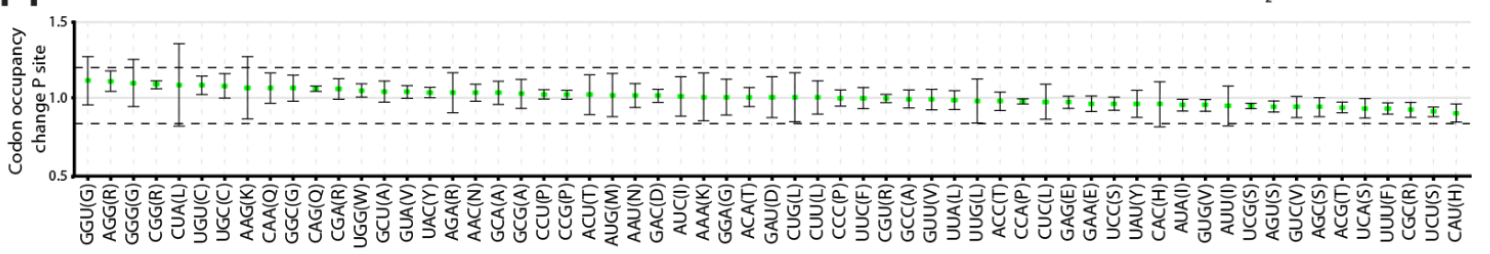

Figure 4. RPL3L usage does not lead to preferential translation or altered translation efficiency. (A) Schematic representation of the Nano-TRAP method. (B) Volcano plots representing differentially expressed input mRNA (left) and ribosome-bound mRNA (right) transcripts identified using Nano-TRAP, which correspond to those with fold change greater than 1 and FDR adjusted p-value lower than 0.05 . Nano-TRAP results show minor differences in transcripts captured in RPL3L- and RPL3-bearing ribosomes. Each dot represents a gene, and they have been colored depending on: i) adjusted p-value $<0.05$ and fold change $>1$ (red), ii) only fold change $>$ 1 (green) or only adjusted $p$-value $<0.05$ (blue), iii) neither fold change $>1$ nor adjusted p-value $<0.05$ (gray). 
See also Table S3 and Table S4. (C) TE analysis using NanoTrap. Counts were normalized by the sum of counts for each sample. Every dot represents a gene. See also Table S5. (D) Schematic representation of the Ribo-Seq method. (E) Percentage of RPF reads mapping to 5' UTR, 3' UTR and CDS regions of identified genes. The values shown are means of three biological replicates. Error bars represent standard deviation. Statistical significance was assessed using the unpaired t-test ( ${ }^{*}$ for $\left.p<0.05\right)$. (F) Metagene analysis of RPF reads from WT and $R p / 3 r^{--}$hearts. (G) Analysis of differential translation efficiency (TE), calculated as the ratio between RPFs and mRNAs (see Methods), between WT and Rp/3 ${ }^{- \text {- }}$ ribosomes. See also Table S6. (H) Codon occupancy change between WT and $R p / 3 H^{--}$at the P-site.

\section{$R p / 3 /$ expression is mutually exclusive with $R p / 3$ expression in cardiomyocytes}

Our results show that $R p / 3 /$ depletion leads to upregulation of $R p / 3$ expression levels, which is concordantly detected both at the mRNA (Figure 2B,4B) and protein levels (Figure 2C,D). Intrigued by this compensatory mechanism, we performed single nuclei RNA sequencing (snRNA-Seq) [39-41] on left ventricles from $R p / 3 /^{+/+}$and $R p / 3 \digamma^{{ }^{-}}$mice, in biological triplicates. Compared to single cell RNA-seq, snRNA-seq improves the profiling of gene expression in cells which are difficult to dissociate from tissues [41].

Analyses of snRNA-seq datasets confirmed that depletion of $R p / 3 /$ showed no major transcriptional changes in cardiomyocytes (Table S7), in agreement with our previous observations (Figure 4B and S11C). Moreover, we confirmed that $R p / 3 /$ is cardiomyocyte-specific, whereas $R p / 3$ is mainly expressed in non-cardiomyocyte cells (Figure S13A). Intriguingly, we observed that $R p / 3$ was also present in some cardiomyocytes. To examine what is the interplay between $R p / 3$ and $R p / 3 /$ expression in cardiomyocytes, we imputed gene expression levels across all the identified single nuclei (see Methods), finding that $R p / 3$ and $R p / 3 /$ are expressed in a mutually exclusive manner (Figure S13B, Table S8). By contrast, this mutual exclusivity was not observed in any of the other ribosomal protein paralog pairs expressed in the heart (Figure S13C and S14). Altogether, our results suggest that the presence of RPL3L in cardiomyocytes is directly responsible for the lack of RPL3 in a given cell.

\section{RPL3-bearing ribosomes establish physical contact with mitochondria}

Our analyses show that $R p / 3$ and $R p / 3 /$ protein-coding sequences significantly differ in their C-terminal region (Figure S2A), which protrudes towards the outer region of the ribosome (Figure 1C). We therefore reasoned that the incorporation of RPL3L or RPL3 in ribosomes could lead to the recruitment of different ribosome-associated proteins (RAPs) [33], which could in turn alter the function or fate of the ribosome.

In order to study how $R p / 3 /$ depletion affects ribosomal protein composition, we employed antibody immunoprecipitation (pulldown of Rpl22-HA-tagged ribosomes from WT or Rp/3\% cardiomyocytes, respectively) coupled to Mass Spectrometry, which we termed Proteo-TRAP (Figure 5A). Our results confirmed that RPL3L was depleted from $R p / 3 T^{--}$cardiomyocytes at the protein level, while RPL3 was upregulated (Figure 5B). The only other RP that was significantly overrepresented in $R p / 3 r^{--}$ 
cardiomyocytes was RPL38, suggesting that the Rp/3/ knockout does not lead to substantial alterations in terms of ribosomal protein composition (Table S9).

To our surprise, ribosomes isolated from $R p / 3 \digamma^{\text {- }}$ cardiomyocytes, which have RPL3-containing ribosomes, showed a dramatic enrichment in mitochondrial proteins. By contrast, this enrichment was absent in WT cardiomyocytes, which have RPL3L-containing ribosomes (Figure 5C, see also Figure S15). GO term enrichment analysis [42] confirmed that proteins that were significantly enriched in mitochondria-related molecular functions and biological processes (Figure 5D). We reasoned that the presence of mitochondrial proteins could be caused by increased physical contact between RPL3-containing ribosomes and mitochondria, relative to RPL3L-containing ribosomes. In this regard, it has been shown that in yeast, ribosomes can localize to the outer mitochondrial membrane, supporting co-translational transport of mitochondrial proteins into the mitochondria [43], with electron cryo-tomography images supporting this hypothesis [44]. On the other hand, it is well documented that mammalian mitochondria also contain ribosome receptors on their outer membrane [45]. To examine whether RPL3 and RPL3L-containing ribosomes might show distinct subcellular localizations, we performed Western blot analyses of cytosolic and mitochondrial fractions of WT and $R p / 3 T^{-1}$ hearts, and found that RPL3 localized to both the cytosolic and the mitochondrial fraction, while RPL3L was almost exclusively detected in the cytosolic fraction (Figure $5 \mathrm{E}$ ). Thus, we conclude that RPL3-containing ribosomes show altered subcellular localization relative to RPL3L-containing ribosomes, causing an increased presence of mitochondrial proteins upon ribosome pulldowns.

Previous works have shown that RPs, including RPL3, can be SUMOylated post-translationally $[46,47]$. In this regard,, we observed that the RPL3 protein that is located in the mitochondrial fraction was of slightly larger size than the one found in the mitochondrial fraction $(\sim 46 \mathrm{kDa})$ (Figure 5E, see also Figure S16). However, the addition of SUMO would account for a $\sim 10 \mathrm{kDa}$ difference, which is larger than $\sim 3 \mathrm{kDa}$ that we observed (Figure S16B). Thus, RPL3 could be a target of yet uncharacterized post-translational modifications, which could account for the observed size difference between the cytosolic and mitochondrial forms. Alternatively, distinct isoforms could be present in mitochondrial-bound RPL3, relative to cytosolic RPL3.

Finally, we examined whether the change in subcellular localization towards the mitochondria would be accompanied by altered mitochondrial function. To this end, we performed luminometric

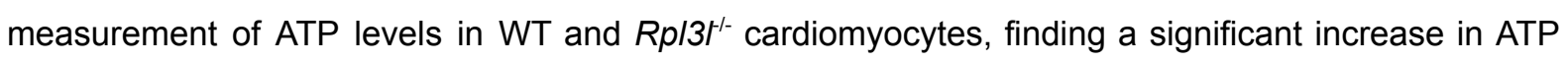
production upon RPL3L depletion (Figure $5 \mathbf{F}$ ). We should note that this global increase in ATP levels was not caused by increased abundance of mitochondria in RPL3L-depleted cardiomyocytes (Figure S17). Future work will be needed to better comprehend how the increased presence of ribosomes bound to the mitochondria leads to increased mitochondrial function. 


\section{A Proteo-trap}

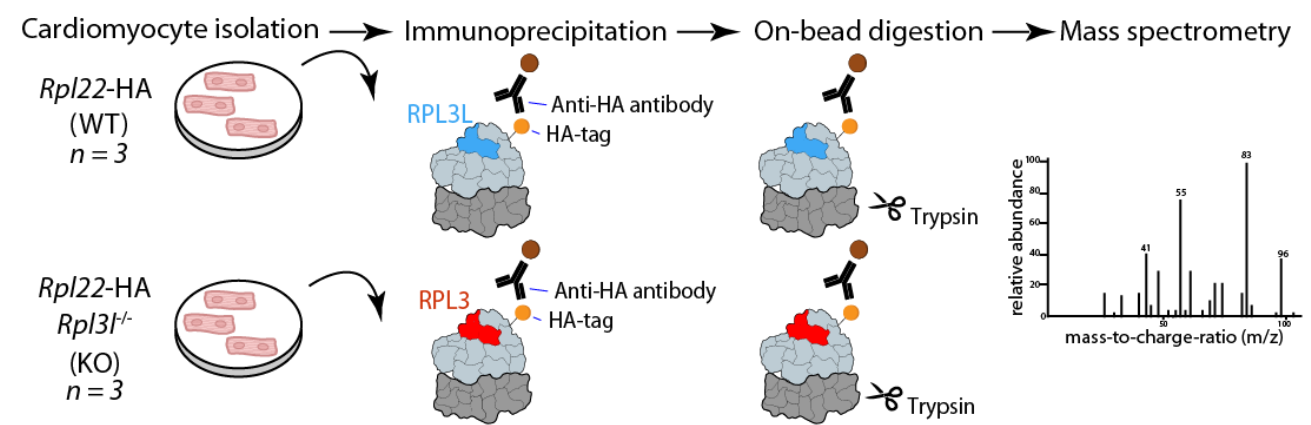

B
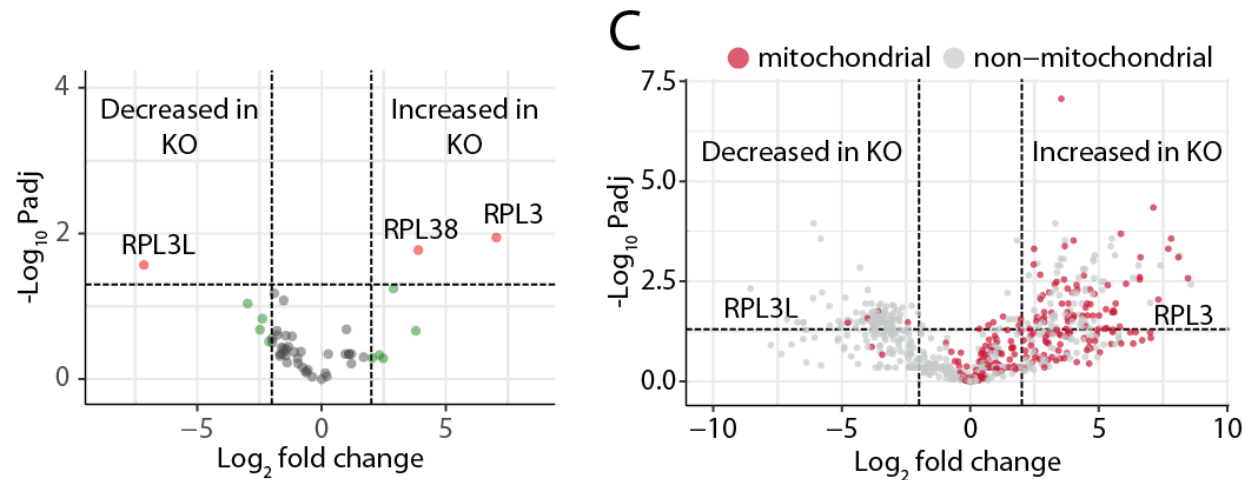

D
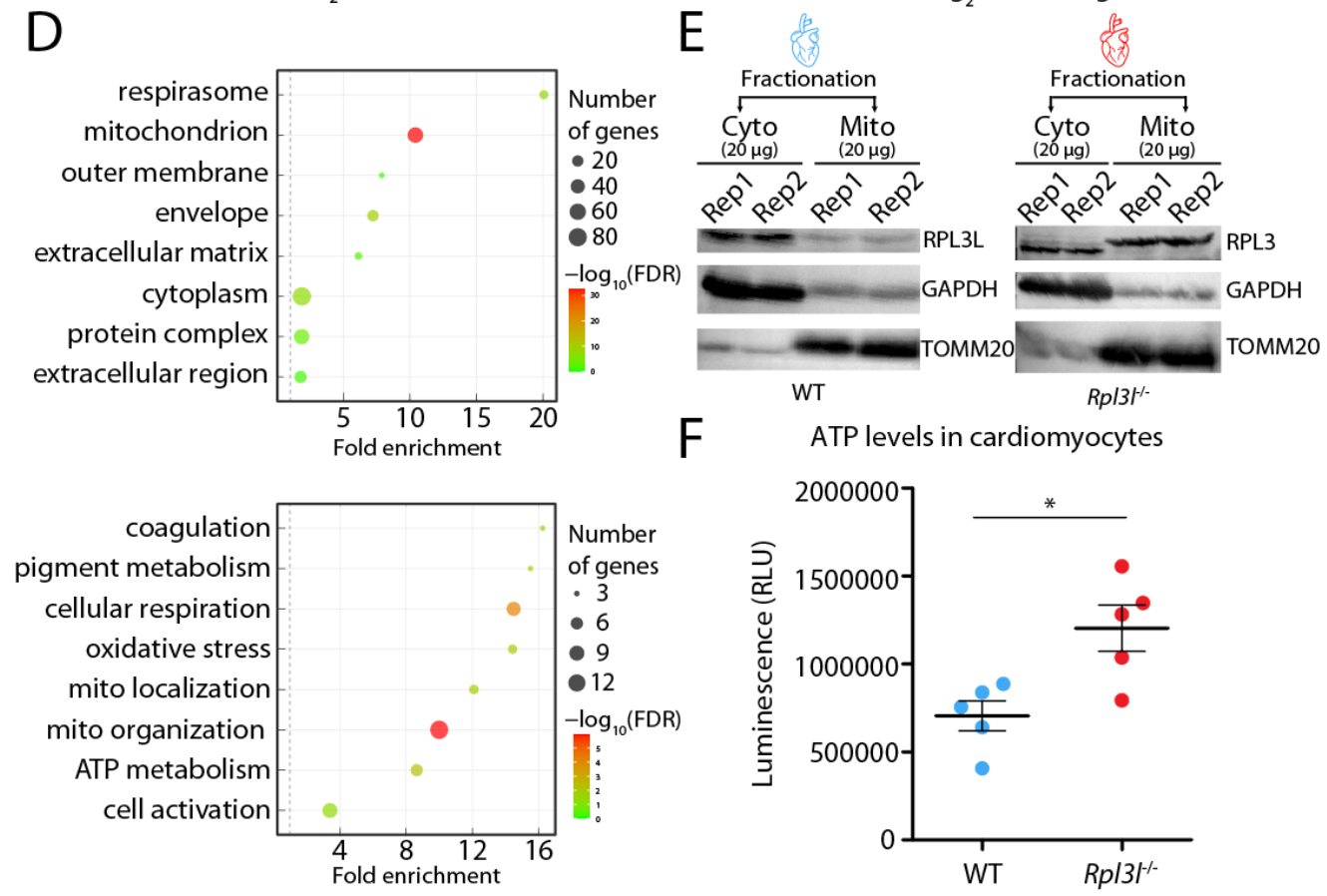

Figure 5. RPL3-containing ribosomes establish physical contact with mitochondria. (A) Schematic representation of the Proteo-TRAP method. (B) Analysis of differential ribosome composition in cardiomyocytes from WT and Rp/3r/ mice. See also Table S9. (C) Volcano plot showing mitochondrial (red) and non-mitochondrial (gray) proteins co-precipitating with ribosomes in WT and $R p / 3{ }^{\prime-}$ cardiomyocytes. See also Table S10 and Figure S15. (D) GO term enrichment plots showing top hits for cellular components (top) and molecular function (bottom). (E) Western blot analysis of cytosolic and mitochondrial fractions of WT (left) and Rp/3r- (right) hearts. GAPDH and TOMM20 were used as cytosolic and mitochondrial fraction markers, respectively. See also Figure S16. (F) Luminometric measurement of ATP levels in WT and Rp/3rcardiomyocytes. Statistical significance was assessed using unpaired t-test $\left({ }^{*}\right.$ for $\left.p<0.05\right)$. 


\section{Hypertrophy leads to increased $R p / 3$ and decreased $R p / 3 /$ levels in the heart}

Cardiac hypertrophy is an adaptive response to pressure or volume stress, mutations of certain proteins, or loss of contractile cardiac mass from prior infarction [48]. Hypertrophy can occur as a compensatory consequence of pressure overload; however, recent studies raise the prospect of modulating hypertrophy to afford clinical benefit without provoking hemodynamic compromise $[49,50]$. To accomplish this goal, it is essential to identify the molecular events that distinguish pathological hypertrophy versus physiological hypertrophy.

Previous work has shown that hypertrophy leads to an increase in $R p / 3$ and a decrease in $R p / 3 /$ mRNA levels in skeletal muscle [14]. Thus, we wondered whether a similar phenomenon may be observed in the heart upon hypertrophy, and to this end we queried several publicly available RNA-seq datasets and examined how RP expression patterns varied upon diverse hypertrophic stimuli [32,51,52]. Firstly, we examined the expression patterns of $R p / 3 /$ of resting and hypertrophic hearts (weeks 2, 5, 8 and 11 post transverse aortic constriction (TAC) surgery) in scRNA-Seq datasets [32], and observed a steady decrease in $R p / 3 /$ levels in cardiomyocytes upon hypertrophic stimulus (Figure S18), with most cardiomyocytes expressing $R p / 3 /$ at the first two timepoints (week 0 and week 2), while being almost undetectable in week 11. Similarly, we examined the RP expression patterns in bulk RNA-Seq of TAC-induced hypertrophic and control mice hearts [51], finding that the $R p / 3 / R p / 3 /$ mRNA ratios were consistently altered in all timepoints after surgery (2, 4, 7 and 21 days) (Figure 6A), whereas this trend was not seen in other RPs (Figure S19). Finally, we examined whether the interplay between $R p / 3 / R p / 3 /$ might be altered upon knockout of Lin28a [52], an RNA-binding protein that directly binds and increases mitochondrial phosphoenolpyruvate carboxykinase 2 (Pck2) mRNA levels, which has been shown to play an important role in maintaining cardiac hypertrophy [52]. Indeed, we found that upon Lin28a knockout, the interplay between $R p / 3$ and $R p / 3 /$ expression patterns upon hypertrophic stimulus was impaired (Figure 6B, see also Figure S20). Altogether, our analyses point to a consistent interplay of $R p / 3$ and $R p / 3 /$ expression levels in cardiomyocytes upon hypertrophic stimuli (Figure 6C), suggesting that $R p / 3 /$ might constitute a promising candidate to achieve physiological hypertrophy, holding promise as potential target for therapeutic intervention. 

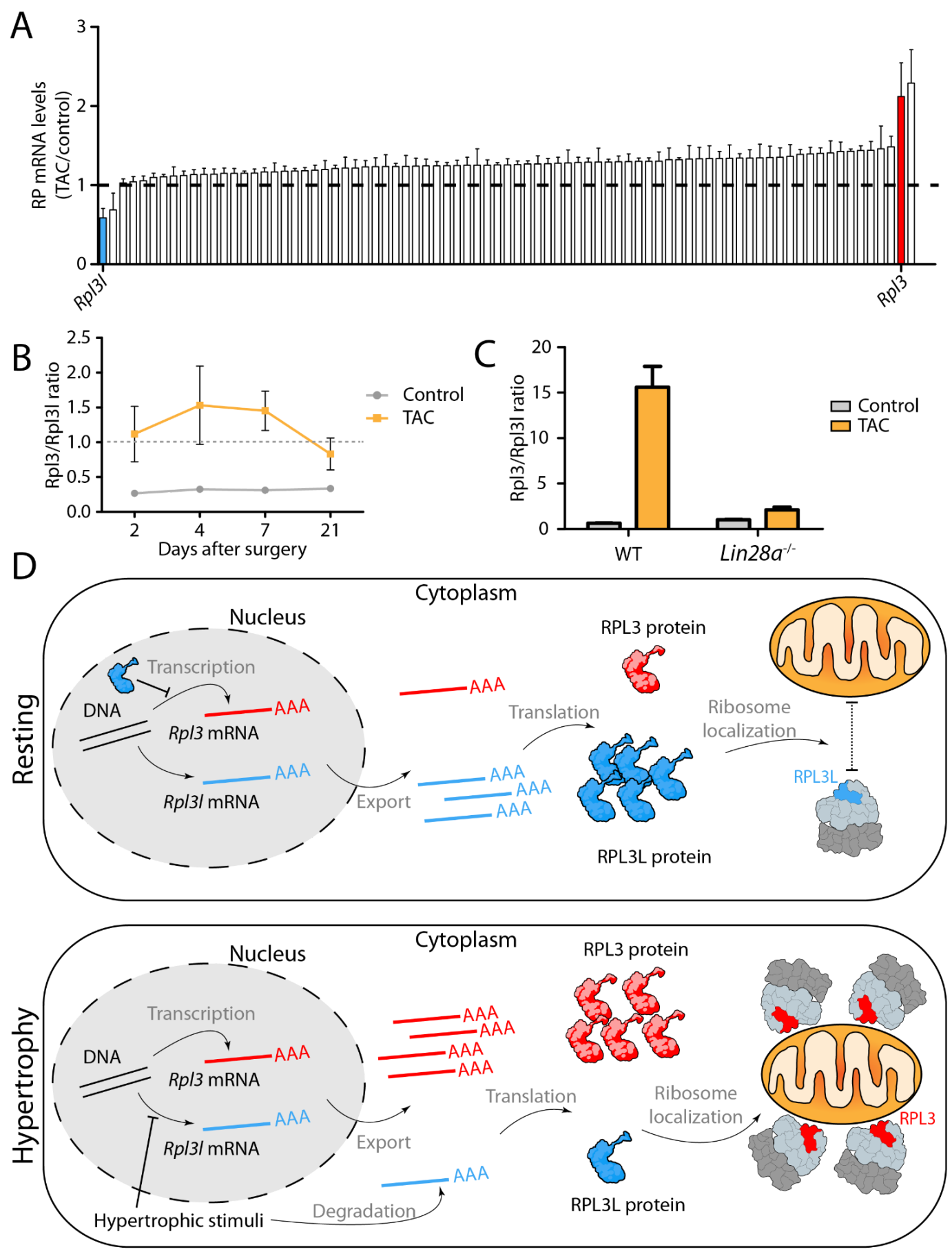

Figure 6. Pressure overload leads to an increase in Rp/3 expression and a decrease in $R p / 3 /$ expression in the heart. (A) Ratio of RP mRNA levels in TAC and control conditions two days after surgery $(n=3) . R p / 3 /$ and $R p / 3$ are colored in blue and red, respectively. See Table S11. (B) Transverse aortic constriction (TAC) leads to heart hypertrophy that correlates with increased Rp/3 expression and decreased Rp/3/ expression. The $R p / 3 / R p / 3 /$ ratio is significantly increased in all timepoints $(2,4,7$ and 21 days after surgery) when compared to control hearts. See also Figure S19. (C) Effects of TAC-induced hypertrophy on Rp/3-Rp/3/ interplay are impaired in Lin28a ${ }^{-1}$ mice. See also Figure S20. (C) Model showing the Rp/3-Rp/3/ interplay in resting (top) and hypertrophic (bottom) conditions. In the resting heart, $R p / 3 /$ is predominantly expressed in cardiomyocytes, and the $R p / 3 /$ protein negatively regulates $R p / 3$ expression, while $R p / 3 /$-containing ribosomes do not establish close contact with mitochondria. Upon hypertrophic stimuli, Rp/3/ expression is impaired and Rp/3/mRNA is degraded in the cytoplasm, leading to an increased expression of $R p / 3$. Rp/3-containing ribosomes establish close contact with mitochondria. 


\section{DISCUSSION}

In recent years, compelling evidence has accumulated supporting ribosome composition heterogeneity $[2,6,8,9,53-55]$. At the level of protein composition, ribosomes lacking specific ribosomal proteins have been shown to exist within mouse embryonic stem cells $[6,8]$, yeast $[3,16,17,56]$ and bacteria [18], though questions remain as to the functionality of such ribosomes [10]. At the level of rRNAs, several studies have shown that these can be expressed from separate genomic loci, with the resulting rRNA molecules differing significantly in their sequences. For example, zebrafish express rRNAs from two separate loci: one locus serves for maternal rRNA transcription, and the other for zygotic rRNA [57]. Similarly, in Plasmodium falciparum, different diverging copies of rRNA are encoded in the genome, one of which is utilized during the mosquito-stage and another during the human-stage of the infection $[58,59]$.

Ribosomal protein (RP) paralogs are present in a wide range of eukaryotic species, but their use as a source of ribosome heterogeneity, as well as their functional relevance, remains unclear. In vertebrates, RP paralogs are believed to have appeared via duplication of the ancestral RP gene [60], can show constitutive or restricted tissue expression profiles $[9,60]$, and their depletion or mutation can lead to tissue-specific phenotypes $[61,62]$. In the case of mice, we find 7 RP paralogs, which display $39-99 \%$ sequence identity to their ancestral gene (Table S12). Here, we examined the functional relevance of RP paralogs in mammals by focusing on the biological role of RPL3L in mice, to unveil why striated muscles in vertebrates evolved to express a distinct version of RPL3, a core RP essential for ribosomal function. Our findings point to a highly specialized function of RPL3L, with its expression being tightly regulated at the temporal level (postnatal expression), restricted to few cell types (myocytes) and in limited subsets of tissues (striated muscles) (Figure 1A,D). Moreover, we find that the C-terminus of RPL3L is the most distinct region when compared to RPL3 (Figure 1B, see also Figure S2A), which is well-conserved among mammalian RPL3L proteins (Figure S2C), suggesting its importance to fulfil its specialized function.

By generating $R p / 3$ and $R p / 3 /$ knockout mouse models, we found that ubiquitously expressed $R p / 3$ is of paramount importance for mouse development, with homozygous Rp/3 knockout being embryonic lethal. We should note that this is not the case of other constitutively expressed RP proteins, such as Rp/22 [63]. By contrast, we successfully generated $R p / 3{ }^{\text {- }}$ homozygous knockout mice, and identified a rescue mechanism in which RPL3 expression levels are upregulated in striated muscles upon Rp/3I depletion (Figure 2B-D, see also Figure S5). Rp/3/- mice showed no apparent histological or physiological aberrations (Figure S6), with no significant differences in their echocardiogram profiles when compared to age-matched wild type mice (Table S2 and Figure S7). By contrast, 55 week old $R p / 3 T^{--}$mice had significantly lower lean mass when compared to age matched wild type mice (Figure $2 F$ ), suggesting that RPL3L might be important for muscle maintenance with aging. 
While previous works have already reported an inverse correlation of $R p / 3$ and $R p / 3 /$ expression upon muscle hypertrophy [14], which we also observe upon $R p / 3 /$ knockout (Figure 2B-D, see also Figure S21), it remains unclear whether RPL3L is incorporated into translating ribosomes, as its putative role could be exclusively extraribosomal. To test this, we performed polysome profiling coupled to western blot analysis on WT and Rp/3r/- hearts, showing that RPL3L is incorporated into polysomes in WT

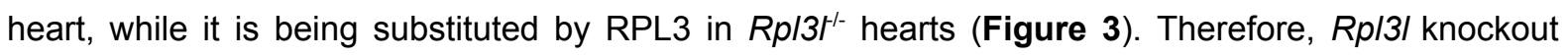
mice offer a model system in which cardiomyocyte ribosomes incorporate RPL3 instead of RPL3L, thus allowing us to study how the use of RPL3 or RPL3L in the ribosome influences translation in in vivo mouse models. We should note that iPSC-derived myocytes cannot be used as a model system to study the RPL3-RPL3L interplay that occurs upon hypertrophy as RPL3L is not expressed in neonatal myocytes [29].

To examine the molecular function of RPL3L in vivo, we first performed Ribo-Seq experiments on both wild type and $\mathrm{Rp} \mid 3 \mathrm{I}^{-{ }^{--}}$hearts, finding that the use of RPL3- or RPL3L-containing ribosomes did not lead to altered translation efficiency of subsets of transcripts (Figure $\mathbf{4 G}$ ). To confirm these observations, we devised a novel method to study preferential translation, consisting of ribosome pulldown (using HA-tagged ribosomes) coupled to Nanopore direct cDNA sequencing, which we termed Nano-TRAP. Our analyses confirmed that $R p / 3 /$ depletion does not lead to preferential translation of transcripts (Figure 4C), in agreement with our observations using Ribo-Seq. Therefore, both orthogonal methods show that $R p / 3 /$ depletion does not lead to global accumulation of ribosome footprints along the transcript nor preferential translation of subsets of transcripts, compared to wild type conditions. We should note that our datasets were not significantly different in terms of coverage than previously published datasets [64], for which we successfully identified differential translation of subsets of transcripts when using the same bioinformatic pipeline (Table S13, see also Figure S22), suggesting that sequencing coverage was not a limiting factor in the identification of differentially translated transcripts in our experiments.

We then investigated whether the stoichiometry of ribosomal proteins (RPs) or ribosome-associated proteins (RAPs) might be altered upon Rp/3/ depletion. To this end, we performed proteomic analyses of ribosome immunoprecipitates (Proteo-TRAP), in a similar fashion to previous works employing FLAG-tagged ribosomes coupled to Mass Spectrometry analyses [6]. Unexpectedly, we found a drastic enrichment of genome-encoded mitochondrial proteins in RPL3-containing ribosome immunoprecipitate fractions, compared to RPL3L-containing fractions (Figure 5C). The fact that such a large number of mitochondrial proteins were found in ribosome immunoprecipitates in RPL3-containing ribosomes (Rpl31 $\left.{ }^{-1} / \mathrm{Rp}^{2} 22 \mathrm{HA}^{+++}\right)$but not in RPL3L-containing ones $\left(\mathrm{Rpl}^{3} \mathrm{l}^{++} / \mathrm{Rpl}^{2} 2 \mathrm{HA} \mathrm{A}^{+/+}\right)$despite stringent washing steps (see Methods) suggests a strong physical contact between RPL3-containing ribosomes and mitochondria. 
It is well-documented that ribosomes can bind to the outer mitochondrial membrane, allowing for co-translational transport of mitochondrial proteins encoded by the nuclear genome [45]. Such findings have been further corroborated by visualization of cytosolic ribosomes on the mitochondrial surface by electron cryo-tomography [44]. In yeast, OM14 has been identified as the mitochondrial receptor of the nascent chain-associated complex, allowing for the binding of ribosomes on the mitochondrial surface [43]. In agreement with these observations, previous studies in yeast have shown that certain strains deficient in specific RP paralogs (Rp/1b, Rp/2b and Rps26b) display altered mitochondrial morphology and function [22]. Moreover, RPL3, in its ribosome-free form, has been shown to have the ability to localize to mitochondria [65]. Based on these previous observations, we speculated that the incorporation of RPL3 into cardiomyocyte ribosomes might lead to tighter ribosome-mitochondria interactions, compared to RPL3L-containing ribosomes, potentially affecting mitochondrial function. To test this, we performed western blot analyses of mitochondrial and cytosolic fractions of WT and Rp/3r- hearts, finding that RPL3L is only detected in the cytosolic fraction, whereas RPL3 localizes both to the cytosolic and the mitochondrial fractions (Figure 5E). We then tested whether the localization of RPL3-containing ribosomes to mitochondria affected their function, finding that the use of RPL3 in ribosomes (present in $\mathrm{Rpl3}^{-/}$cardiomyocytes) was accompanied by a significant increase in ATP levels (Figure 5F), compared to RPL3L-containing ribosomes (present in wild type cardiomyocytes). Future work will be needed to further dissect how the Rp/3-Rp/3/ interplay regulates mitochondrial activity.

Previous studies focusing on hypertrophy have shown that RPL3L levels decrease and RPL3 levels increase in muscle upon hypertrophic stimulus [14] as well as in Duchenne Muscular Dystrophy [66], supporting its importance in muscle function. Similarly, our analyses using publicly available sc-RNAseq datasets showed that RPL3L is downregulated in cardiomyocytes upon hypertrophic stimuli (Figure 6A,B see also Figure S18). Therefore, our Rp/3/ knockout mouse models may constitute a promising in vivo model to study hypertrophy. Notably, a recent study showed that knockdown of RPL3L improved muscle function [66], but the underlying molecular mechanism remains unclear. We propose that the improved muscle function observed in these studies $[14,66]$ might be a direct consequence of altered mitochondrial activity upon RPL3L downregulation, in a similar fashion to what we observe upon $R p / 3 /$ depletion (Figure $\mathbf{5 F}$ ).

The dynamic interplay between mammalian RP paralogs is not an exclusive feature of the Rp/3-Rp/3/ pair, but has also been reported to occur in other paralog pairs, such as the Rp/22-Rp/22/1 pair. Specifically, homozygous depletion of $R p / 22$ in mice is compensated by an upregulation of its paralog RPL22L1 [63], which is otherwise largely absent in its protein form in most adult tissues (Figure 1A). Intrigued by this molecular interplay, we examined previously published genome-wide epigenetic chromatin states [67] of distinct RP paralog pairs across a wide variety of tissues, finding that both $R p / 3$ and $R p / 3 /$ genes show active translation chromatin states in adult striated muscle tissues but not 
in other tissues (Figure S23), suggesting that both genes are actively transcribed, and therefore, that the interplay between $R p / 3$ and $R p / 3 /$ most likely occurs at the mRNA level. In agreement with these observations, a recent study in yeast showed that the interplay between Rp/22a and Rp/22b occurred at the mRNA level, where the RPL22A protein was shown to bind the intron of the unspliced Rp/22b RNA transcript, causing its degradation [68]. We speculate that a similar regulatory mechanism could be present in vertebrates, and could potentially explain how the $R p / 3-R p / 3 /$ interplay that occurs upon hypertrophic stimuli is achieved (Figure S18 and S19).

RPL3 is a highly conserved core ribosomal protein that plays an important role in ribosome function, and mutation of key residues of yeast RPL3 has been shown to cause altered peptidyltransferase activity and frameshifting efficiency [69]. On the other hand, methylation of $\mathrm{H} 243$ in S. cerevisiae has been shown to affect translation elongation and translational fidelity [70]. More recently, studies in yeast have shown that the mutation of W255, the residue that is closest to the peptidyl- transferase centre, affected diverse aspects of ribosome biogenesis and function [34]. Thus, we speculate that while the selective use of RPL3 and RPL3L in cardiomyocytes does not affect translation efficiency, it might be affecting translational fidelity. Future work will be needed to decipher whether the incorporation of RPL3 or RPL3L into ribosomes might be significantly affecting translational fidelity in mammals.

Altogether, our work shows that $R p / 3 /$ is a cell-type specific paralog of $R p / 3$ that is restricted to myocyte cells in adult striated muscle tissues, which is downregulated upon hypertrophic stimuli. We show that although RPL3L is incorporated into actively translating ribosomes, it does not lead to preferential translation nor to altered translation efficiency, as demonstrated by Ribo-Seq and Nano-TRAP. By contrast, we show that the use of RPL3L or RPL3 modulates the subcellular location of ribosomes and mitochondrial activity in cardiomyocytes. Our work expands our understanding of mammalian RP paralogs and their functional relevance in vivo, supporting the view that ribosome heterogeneity is accompanied by functional specialization.

\section{MATERIALS AND METHODS}

\section{Generation of Rpl3 and Rpl3I knockout mice}

$R p / 3^{+-}$and $R p / 3 \%^{--}$mice were produced by the Mouse Engineering Garvan/ABR (MEGA) Facility (Moss Vale and Sydney, Australia) using CRISPR/Cas9 gene targeting in C57BL/6J mouse embryos following established molecular and animal husbandry techniques [71]. The single guide RNAs (sgRNAs) employed were based on the following target sequences (protospacer-associated motif = PAM italicised and underlined): Rp/3 (Exon 6) TTCCAGGGGTAACCAGTCGT $\underline{T G G}$ and Rp/3l (Exon 5)

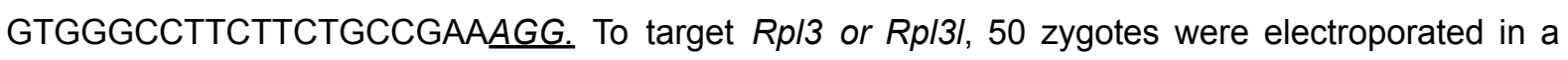
solution containing the specific sgRNA (300 $\mathrm{ng} / \mu \mathrm{L})$ and Cas9 mRNA (600 $\mathrm{ng} / \mu \mathrm{L})$. Embryo preparation 
and electroporation was carried out according to the method of Qin et al [72], except that zygotes were incubated for $25 \mathrm{~s}$ (not $10 \mathrm{~s}$ ) in acidic Tyrode's solution and received three (not two) pulses. Microinjected or electroporated embryos were cultured overnight and those that underwent cleavage were introduced into pseudo-pregnant foster mothers. Pups were screened by PCR across the target site and Sanger sequencing of PCR products to detect modifications to the targeted gene. Founders carrying frameshift deletions were backcrossed to wild-type C57BL/6J mice and heterozygous progeny then inter-crossed. Viable homozygous mice were generated at normal Mendelian frequencies in the case of the $R p / 3 /^{\Delta}$ lines whereas homozygous $R p / 3^{\Delta}$ mice all showed prenatal lethality.

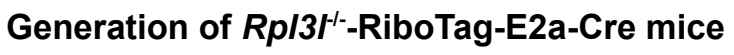

RiboTag mice were purchased from The Jackson Laboratory (Stock No: 011029). This mouse line, generated by the McKnight lab [73], carries a floxed wild-type C-terminal exon in the Rp/22 gene, followed by a mutant exon that has a triple hemagglutinin (HA) epitope inserted in front of the stop codon, leading to the generation of HA-tagged ribosomes when crossed with a Cre-expressing mouse strain. The RiboTag mice were first crossed with the E2a-Cre mouse line, also purchased from The Jackson Laboratory (Stock No: 003724) and bred to homozygous genotype, ensuring the excision of the wild-type C-terminal exon and the expression of HA-tagged Rp/22 in all tissues. These mice were then crossed with the $R p / 3 r^{-}$strain and bred to obtain a homozygous genotype.

\section{Mice tissue collection}

All experiments were performed with male mice aged between 8 and 10 weeks, unless stated otherwise. All mice were euthanized using $\mathrm{CO}_{2}$, except for the Ribo-Seq, Nano-TRAP and single nuclei RNA-Seq experiments, for which mice were euthanized using cervical dislocation, and tissues were snap frozen in liquid nitrogen.

\section{Total RNA extraction from mice tissues}

Tissues were homogenized in TRIzol (Life Technologies, 15596018) using the Polytron PT $1200 \mathrm{E}$ hand homogenizer in pulses of 10 seconds at maximum speed until thoroughly homogenized. Total RNA was extracted using ethanol precipitation, and purity and concentration were measured using NanoDrop spectrophotometer.

\section{Body composition measurements using magnetic resonance imaging (MRI)}

The body composition of 8 week old male and 55 week old female $R p / 3 r^{--}$and $R p / 3{ }^{H^{++}}$mice was analysed using the EchoMRI ${ }^{\mathrm{TM}}-100 \mathrm{H}$ Body Composition Analyser without anesthetizing. The EchoMRI $^{\mathrm{TM}}-100 \mathrm{H}$ delivers precise body composition measurements of fat, lean, free water and total water masses in live animals. Statistical significance of the results was assessed using unpaired t-test. 


\section{Histopathological analyses of Rpl $3^{-/-}$knockout and control mice}

A complete necropsy of 8 week old male $R p / 3 r^{--}$and $R p / 3 I^{+++}$mice $(n=5)$ was performed to check for possible macroscopic findings. Mice were weighed before euthanasia with $\mathrm{CO}_{2}$. The heart and brain were weighed in order to obtain the body weight to organ and brain-organ ratios. The right quadriceps, right gastrocnemius and apex of the heart were embedded in optimal cutting temperature compound (OCT) and were frozen straight away. The left quadriceps, left gastrocnemius and the whole heart (excluding the apex) were collected and fixed in buffered $4 \%$ paraformaldehyde overnight and transferred to PBS. The tissues were then trimmed, paraffin embedded, sectioned (3-4 $\mu \mathrm{m}$ tissue sections) and stained with Haematoxylin/Eosin (H\&E). All the hearts were trimmed transversally at the same level in order to obtain a biventricular short axis section (biventricular, transversal). The proximal area of the gastrocnemius and quadriceps were trimmed transversally, and the remaining tissue was sectioned longitudinally. At least three cross sections of each heart were evaluated in a blinded manner in order to detect histopathological changes of the myocardium such as disarray, myocardial degeneration, hypertrophy or atrophy and other possible alteration such as inflammation or fibrosis. Furthermore, quantitative analysis of the left ventricle, right ventricle and myocardial fibres was performed using the NDP.view 2 2.8.24 software (Hamamatsu). The measurements of the left and right ventricular free walls were performed as previously reported [74], with a single line from the endocardium to the pericardium oriented as perpendicular as possible to both surfaces, always at areas without papillary muscle. Five measurements were performed preferably in the same cross section, except in cases that it was not possible. The muscle samples were evaluated in a blinded manner in order to detect histopathological changes such as sarcoplasmic enlargement or thinning, vacuolization or nuclear centralisation (signs of degeneration or atrophy) and other possible alterations such as inflammation or fibrosis. A description of the main histological features present was done using the following semi-quantitative grading system: 1 ; minimal, 2; mild, 3; moderate, 4; marked, 5; severe.

\section{Echocardiography analyses of Rpl $3^{-/-}$knockout and control mice}

Anaesthesia was induced in mice using 5\% isoflurane then weighed and transferred to a warming pad $\left(40{ }^{\circ} \mathrm{C}\right)$ with built in ECG for heart rate (HR) determination. The pad is integrated into the Vevo3100 (Fuijifilm SonoSite, Inc., WA, USA) ultrasound system. An MX400 probe was used for all assessments. The chest was shaved, washed and ultrasound gel applied. Isoflurane was adjusted to keep HR as close to 500 BPM as possible while inhibiting the righting reflex. Systolic function was assessed from single high resolution ECG gated B-mode cine-loops (EKV). Endocardial and epicardial volumes were determined using the bullet formula Vol $=5 / 6 \times L \times A$, where $A$ is the area determined by planimetry at the mid-papillary level and $L$ is long axis length from the junction of aortic leaflets to the apical dimple. stroke volume (SV) was calculated as the difference between endocardial volumes at end diastole (ED) and end systole (ES), EDV and ESV respectively. Ejection fraction (EF) 
was calculated as SV / EDV. ED was defined as the beginning of the ECG R-wave upstroke and ES as the closure of the aortic valve. Diastolic function was assessed using pulse-wave and tissue Doppler from an apical 4-chamber view of the mitral valve. Left atrial dimension was determined as the diameter along a line aligned to the inferior edge of the aortic annulus in a parasternal long axis B-mode image at end-systole.

\section{RT-qPCR}

Total RNA isolated from mouse tissues was used as starting material for qPCR reactions. Briefly, total RNA was first DNase-treated with TURBO ${ }^{\text {TM }}$ DNase (Life Technologies, AM2239) for 30 minutes at 37 ${ }^{\circ} \mathrm{C}$ to remove possible DNA contamination. Total RNA was then re-extracted using acid phenol-chloroform (Life Technologies, AM9720) and quantified using NanoDrop spectrophotometer. $100 \mathrm{ng}$ of total RNA was mixed with Oligo(dT) primers, random hexamers and 10mM dNTP mix (Invitrogen, 18080051). The reaction mixture was heated to $65^{\circ} \mathrm{C}$ in a thermocycler, after which it was quickly chilled on ice. RNase inhibitors (Invitrogen ${ }^{\mathrm{TM}}$ RNaseOUT $^{\mathrm{TM}}$ ), $0.1 \mathrm{M}$ DTT and the First-strand buffer (Invitrogen, 18080051) were added to the reaction mixture which was incubated at $42^{\circ} \mathrm{C}$ for 2 minutes. SuperScript ${ }^{\mathrm{TM}}$ II reverse transcriptase (Life Technologies, 18064-014) was finally added, and the reaction mixture was incubated at $42{ }^{\circ} \mathrm{C}$ for 50 minutes, followed by a 15 minutes-long inactivation at $70{ }^{\circ} \mathrm{C}$. The synthesized cDNA was diluted $1: 6$ and used for the $\mathrm{qPCR}$ reaction. The Power SYBR Green Master Mix (Life Technologies, A25741) was used as the fluorescent dye, and the primers were used as follows: Rp/3_fw: GGAAAGTGAAGAGCTTCCCTAAG, Rp/3_rev: CTGTCAACTTCCCGGACGA, Rp/3I_fw: GAAGGGCCGGGGTGTTAAAG, Rp/3I_rev: AGCTCTGTACGGTGGTGGTAA, GAPDH_fw: AGCCTCGTCCCGTAGACAAA, GAPDH_rev: AATCTCCACTTTGCCACTGC. All oligonucleotide sequences used in $\mathrm{qPCR}$ experiments can be found in Table S14. The LightCyclerß 480 Instrument II was used for the qPCR reaction with the following programme: $90^{\circ} \mathrm{C}, 2 \mathrm{~min} ; 40$ cycles of $90^{\circ} \mathrm{C}, 5 \mathrm{~s} ; 60^{\circ} \mathrm{C}, 10 \mathrm{~s} ; 72^{\circ} \mathrm{C}, 20 \mathrm{~s}$.

\section{Quantification of mitochondrial genome copy number}

Mitochondrial DNA (mtDNA) quantification was performed according to Quiros et al. [75]. Briefly, mice were euthanized and hearts were collected and cut into small pieces. 10-30 mg of tissue was then transferred to an ice cold $1.5 \mathrm{~mL}$ eppendorf tube and $600 \mu \mathrm{L}$ of lysis buffer $(100 \mathrm{mM} \mathrm{NaCl}, 10 \mathrm{mM}$ EDTA, $0.5 \%$ SDS, $20 \mathrm{mM}$ Tris- $\mathrm{HCl} \mathrm{pH} 7.4$ ) was added, followed by $0.2 \mathrm{mg} / \mathrm{mL}$ of proteinase $\mathrm{K}$. The samples were incubated overnight at $55^{\circ} \mathrm{C}$. The next day, $100 \mu \mathrm{g} / \mathrm{mL}$ of RNase A (Qiagen, 158922) was added and the samples were incubated for 30 minutes at $37^{\circ} \mathrm{C} .600 \mu \mathrm{L}$ of ultrapure phenol: chloroform: isoamyl alcohol $(25: 24: 1, \mathrm{v} / \mathrm{v})$ was added and mixed well. The samples were centrifuged at $12,000 \times \mathrm{g}$ for 5 minutes, and the aqueous phase was transferred to a new tube. $250 \mu \mathrm{L}$ of $7.5 \mathrm{M}$ ammonium acetate and $600 \mu \mathrm{L}$ of isopropanol $(0.7 \mathrm{v} / \mathrm{v})$ were mixed well. The samples were then centrifuged at $15,000 \times \mathrm{g}$ for 10 minutes at $4{ }^{\circ} \mathrm{C}$. The supernatant was discarded, and the pellet was washed with $500 \mu \mathrm{L}$ of $70 \%$ ethanol. The pellet was air-dried and resuspended in TE buffer $(10 \mathrm{mM}$ 
Tris- $\mathrm{HCl} \mathrm{pH} 7.4$ and $1 \mathrm{mM}$ EDTA). Concentration was measured using NanoDrop and the samples were diluted to $10 \mathrm{ng} D N A / \mu \mathrm{L}$. qPCR was done as previously described. The primers were used as follows: mt16S_fw: CCGCAAGGGAAAGATGAAAGAC, mt16S_rev: TCGTTTGGTTTCGGGGTTTC, Nd1_fw: CTAGCAGAAACAAACCGGGC, Nd1_rev: CCGGCTGCGTATTCTACGTT, Hk2_fw: GCCAGCCTCTCCTGATTTTAGTGT, Hk2_rev: GGGAACACAAAAGACCTCTTCTGG.

\section{Polysome profiling}

Whole hearts were cut into small pieces and homogenized in pre-chilled $2 \mathrm{~mL}$ eppendorf tubes using

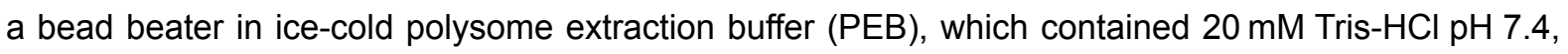
$200 \mathrm{mM} \mathrm{KCl}, 10 \mathrm{mM} \mathrm{MgCl} 2,1 \mathrm{mM} \mathrm{DTT}, 0.1 \mathrm{mg} / \mathrm{mL}$ of cycloheximide, $10 \mathrm{U} / \mathrm{mL}$ of DNasel (NEB, M0303S), 1x cOmplete ${ }^{T M}$ protease inhibitor cocktail (Roche, 11873580001) and $100 \mathrm{U} / \mathrm{mL}$ of RNAse inhibitors (RNaseOUT, Invitrogen, no. 18080051) using the following program: 2 cycles of 15 seconds, 1 minute incubation on ice and 1 cycle of 30 seconds. The homogenates were incubated for 5 minutes on ice and then centrifuged at $20.000 \times \mathrm{g}$ for 12 minutes at $4{ }^{\circ} \mathrm{C}$. Triton $\mathrm{X}-100$ was added to the final concentration of $1 \%$, and the homogenates were incubated for 30 minutes on an end-over-end rotator at $4{ }^{\circ} \mathrm{C}$. The samples were then centrifuged in a benchtop centrifuge at maximum speed for 12 minutes and the supernatant was transferred to a new tube. Linear sucrose gradients of $10-50 \%$ were prepared using the Gradient Station (BioComp). Briefly, SW41 centrifugation tubes (Beckman Coulter, Ultra-ClearTM 344059) were filled with Gradient Solution 1 (GS1), which consisted of $20 \mathrm{mM}$ Tris- $\mathrm{HCl} \mathrm{pH} 8,200 \mathrm{mM} \mathrm{KCl}, 10 \mathrm{mM} \mathrm{MgCl} 2,0.2 \mathrm{mg} / \mathrm{mL}$ of cycloheximide and 10\% wt/vol RNAse-free sucrose. Solutions GS1 and Gradient Solution 2 (GS2) were prepared with RNase/DNase-free UltraPure water and filtered with a $0.22-\mu \mathrm{m}$ filter. The tube was then filled with $6.3 \mathrm{~mL}$ of GS2 layered at the bottom of the tube, which consisted of $20 \mathrm{mM}$ Tris- $\mathrm{HCl} \mathrm{pH} \mathrm{8,} 200 \mathrm{mM} \mathrm{KCl}, 10 \mathrm{mM} \mathrm{MgCl} 2,0.2 \mathrm{mg} / \mathrm{mL}$ of cycloheximide and $50 \%$ wt/vol RNAse-free sucrose. The linear gradient was formed using the tilted methodology, with the Gradient Station Maker (BioComp). Once the gradients were formed, $700 \mu$ of each lysate was carefully loaded on top of the gradients, and tubes were balanced in pairs, placed into pre-chilled SW41Ti buckets and centrifuged at $4^{\circ} \mathrm{C}$ for 150 minutes at 35,000 r.p.m. Gradients were then immediately fractionated using the Gradient Station, and $20 \times 500 \mu \mathrm{L}$ fractions were collected in $1.5 \mathrm{~mL}$ Eppendorf tubes while absorbance was monitored at $260 \mathrm{~nm}$ continuously. Neighboring fractions were pooled together (i.e. fractions 1 and 2, fractions 3 and 4, etc.), concentrated using Amicon-Ultra 100K columns (Millipore) and washed two times with cold PEB. The final volume was brought down to $200 \mu \mathrm{L}$, which was subsequently used for western blot analysis.

\section{Isolation of the mitochondrial fraction}

The mice were euthanized by cervical dislocation and the hearts were quickly excised and placed into ice cold BIOPS (10 mM Ca-EGTA, $0.1 \mu \mathrm{M}$ free calcium, $20 \mathrm{mM}$ imidazole, $20 \mathrm{mM}$ taurine, $50 \mathrm{mM}$ K-MES, $0.5 \mathrm{mM}$ DTT, $6.56 \mathrm{mM} \mathrm{MgCl}_{2}, 5.77 \mathrm{mM}$ ATP, $15 \mathrm{mM}$ phosphocreatine, pH 7.1). Blood clots 
were carefully removed and the hearts were cut into small pieces using cooled scissors. The tissue was transferred into a $2 \mathrm{~mL}$ Dounce homogenizer, and $1 \mathrm{~mL}$ of isolation buffer $\mathrm{B}$ ( $225 \mathrm{mM}$ mannitol, $75 \mathrm{mM}$ sucrose, $1 \mathrm{mM}$ EGTA, $2.5 \mathrm{mg} / \mathrm{mL}$ BSA, $0.5 \mathrm{mg} / \mathrm{mL}$ subtilisin) was added. The tissue was homogenized at medium speed in 6-8 strokes. The homogenate was transferred to a $15 \mathrm{~mL}$ falcon tube and $1.5 \mathrm{~mL}$ of isolation buffer $\mathrm{B}$ was added. The homogenate was centrifuged at $800 \mathrm{~g}$ for 10 minutes at $4{ }^{\circ} \mathrm{C}$. The supernatant was transferred to a new $15 \mathrm{~mL}$ falcon tube, and centrifuged at $10,000 \mathrm{~g}$ for 10 minutes at $4{ }^{\circ} \mathrm{C}$. The supernatant was saved for subsequent western blot analysis of the cytoplasmic fraction. The mitochondrial pellet was carefully resuspended in $1 \mathrm{~mL}$ of isolation buffer $A$ (isolation buffer $B$ without subtilisin) and centrifuged at $10,000 \mathrm{~g}$ for 10 minutes at $4{ }^{\circ} \mathrm{C}$. The supernatant was discarded and the mitochondrial pellet was lysed in $300 \mu \mathrm{L}$ of ice-cold RIPA buffer. The lysate was used for subsequent western blot analysis.

\section{Protein extraction and Western Blot}

Frozen tissues were chopped into smaller pieces and homogenized in ice-cold RIPA buffer using the Polytron PT $1200 \mathrm{E}$ hand homogenizer in pulses of 10 seconds at maximum speed until thoroughly homogenized. The homogenates were then agitated on an end-over-end shaker at $4{ }^{\circ} \mathrm{C}$ for 2 hours. Finally, the homogenates were centrifuged for 20 minutes at $12,000 \mathrm{rpm}$ at $4{ }^{\circ} \mathrm{C}$ in a microcentrifuge. The supernatant was placed in a new tube and kept on ice, and the pellet discarded. Protein concentration was measured using the Bradford assay, and $\sim 15 \mu \mathrm{g}$ of total protein was mixed with the NuPAGE ${ }^{\mathrm{TM}}$ LDS Sample Buffer supplemented with NuPAGE ${ }^{\mathrm{TM}}$ Sample Reducing Agent, incubated at $70{ }^{\circ} \mathrm{C}$ for 10 minutes and loaded onto a $12 \%$ polyacrylamide gel. The electrophoresis was run at $80 \mathrm{~V}$ until the samples reached the resolving gel, when the voltage was increased to $120 \mathrm{~V}$. The transfer was performed onto a PVDF membrane in a Bolt ${ }^{\mathrm{TM}}$ Mini Gel Tank, at a constant voltage of $20 \mathrm{~V}$ for 50 minutes. The membrane was then washed three times for 5 minutes in TBST, after which it was blocked for 1 hour in 3\% BSA in TBST (blocking buffer). The incubation with the primary antibodies (Rpl3 Rabbit Polyclonal Antibody (Proteintech, 11005-1-AP); Rpl3I Rabbit Polyclonal Antibody (custom-made, kindly provided by Prof. John McCarthy); Rpl7 Rabbit Polyclonal Antibody (Abcam, ab72550); Tomm20 Rabbit Polyclonal Antibody (Abcam, ab78547) was done in blocking buffer overnight at $4{ }^{\circ} \mathrm{C}$ at a 1:1000 dilution. The next day, the membrane was washed three times for 5 minutes, and incubated in the secondary HRP-coupled antibody (Abcam, ab6721) at a 1:10,000 dilution in a blocking buffer for 1 hour at room temperature. The membrane was washed three times and imaged using the SuperSignal ${ }^{\mathrm{TM}}$ West Pico PLUS Chemiluminescent Substrate. The membrane was then reprobed with an anti-GAPDH antibody (1:1000 in blocking buffer) for one hour, and reimaged the same way. Full images of all western blots shown in this work can be found in Figures

\section{S4-5, Figure S8 and Figure S16.}




\section{Immunofluorescence assays}

Freshly collected heart and muscle tissues were quickly frozen with OCT (Optimal cutting temperature compound) and cut in $12 \mu \mathrm{m}$ thickness slices using a cryotome. The slices were circled with a hydrophobic marker and incubated with $4 \%$ formaldehyde in PBS for 10 minutes at room temperature. The slides were then washed in PBS in staining jars three times for 5 minutes. To ensure the permeabilization of the cells, the samples were incubated with $0.5 \%$ Triton-X-100 in PBS for 30 minutes at $4{ }^{\circ} \mathrm{C}$. Three washes with PBS were repeated, and the tissues were blocked with $3 \%$ BSA in TBS-T for 30 minutes at room temperature. The slides were washed with TBS-T three times for 5 minutes, and incubated with the primary antibodies (Rpl3 Rabbit Polyclonal Antibody (Proteintech, 11005-1-AP); Rpl3I Rabbit Polyclonal Antibody (custom-made in the lab of Prof. John McCarthy); anti-Atp5a Mouse Monoclonal Antibody (Abcam, ab14748) in blocking solution at a dilution of 1:200 (5 $\mu \mathrm{g} / \mathrm{mL}$ in the case of anti-Atp5a) overnight at $4{ }^{\circ} \mathrm{C}$. The next day, the samples were washed with TBS-T three times for 5 minutes, and incubated in the secondary antibody mixture (Anti-Rabbit Secondary Antibody Alexa Fluor 555 (Thermo Fisher Scientific, A-21429) 1:400, Phalloidin-iFluor 488 (Abcam, ab176753), 1:1000 and Hoescht 33342 (Thermo Fisher Scientific, H3570) 1:1000 in blocking solution) for one hour at room temperature. The slides were then washed with TBS-T three times for 5 minutes, air-dried for a few minutes and mounted with coverslips. The immunofluorescence images were made using the Leica TCS SPE confocal microscope.

\section{Luminometry assays for ATP quantification}

Cardiomyocytes isolated from WT and $R p / 3 r^{-}$hearts were diluted to same concentrations and the cell suspensions were mixed with the same volume of CellTiter-Glo (Promega, G7570), as instructed by the manufacturer. The reaction mixtures were pipetted into wells of an opaque 96-well plate and mixed for 2 minutes on an orbital shaker. The plate was then incubated for 10 minutes at room temperature and the luminescence was read using the Berthold LB 960 Microplate Luminometer.

\section{Phylogenetic analysis}

To obtain a phylogenetic analysis of the $R p / 3 / R p / 3 /$ family, full proteomes of representative species [76] were downloaded from Uniprot. A Hidden Markov Model (HMM) profile of RPL3 (PF00297) was downloaded from Pfam [77], and was used to query the selected proteomes using the hmmsearch function from the HMMER package (version 3.3) [78]. Hits were then aligned to the HMM using the hmmalign function from HMMER, and a phylogenetic tree was built using the maximum likelihood method of IQ-TREE (version 1.6.11) [79,80]. The final tree was visualized using FigTree (version 1.4.4) [81]. Code to reproduce the phylogenetic analyses is available in GitHub: https://github.com/imilenkovic/RPL3L/tree/main/Phylogeny. 


\section{Analysis of ribosomal protein expression patterns across mouse tissues and developmental stages}

Previously published RNA-seq data [29] was used for the expression analysis. The RPKM values for all tissues across the time-series were downloaded from the ArrayExpress EBI repository (https://www.ebi.ac.uk/arrayexpress/files/E-MTAB-6798/E-MTAB-6798.processed.1.zip). RPK values corresponding to ribosomal proteins were extracted from the full list, and the median expression values were calculated from biological replicates. The ComplexHeatmap R package was used to construct the heatmaps shown in Figure 1 and Figure S1, and the code to reproduce the heatmap figures can be found in GitHub: https://github.com/imilenkovic/RPL3L/tree/main/ComplexHeatmap.

\section{Ribosome pulldown using anti-HA antibodies (for Nano-TRAP)}

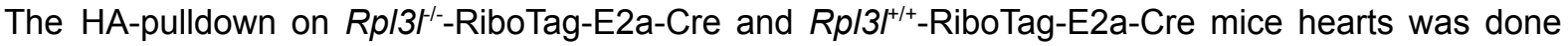
using a modified approach devised by Sanz et al. [82]. The mice were euthanized using cervical dislocation, and the hearts were excised, removing the aorta and the atria. The hearts were placed in ice-cold PBS supplemented with $100 \mu \mathrm{g} / \mathrm{mL}$ cycloheximide (CHX) and the blood was removed by gently squeezing with forceps. While on ice, the hearts were chopped to smaller pieces and added to pre-chilled $2 \mathrm{~mL}$ tubes containing $\sim 100 \mu \mathrm{L}$ of acid-washed glass beads (425 - $600 \mu \mathrm{m})$ and $1 \mathrm{~mL}$ of homogenization buffer $(50 \mathrm{mM}$ Tris- $\mathrm{HCl}, \mathrm{pH} 7.5 ; 100 \mathrm{mM} \mathrm{KCl} ; 12 \mathrm{mM} \mathrm{MgCl}$; $1 \%$ Nonidet P-40 substitute; $1 \mathrm{mM}$ DTT; $200 \mathrm{U} / \mathrm{mL}$ RNasin; $1 \mathrm{mg} / \mathrm{mL}$ heparin; $100 \mu \mathrm{g} / \mathrm{mL}$ cycloheximide; 1× protease inhibitor mixture). The hearts were then homogenized using a Mini Beadbeater (BioSpec Products) in 2 cycles of 60 seconds and 1 cycle of 15 seconds, allowing the samples to cool down on ice for 1 minute between the cycles. The lysates were cleared by centrifuging for 10 minutes at $10,000 \times \mathrm{g}$ at 4 ${ }^{\circ} \mathrm{C}$. The supernatants were transferred to pre-chilled DNA LoBind tubes, and small aliquots of $40-80$ $\mu \mathrm{L}$ were transferred to separate tubes and kept at $-80{ }^{\circ} \mathrm{C}$ for subsequent input analysis. $4 \mu \mathrm{L}$ of anti-HA antibody (BioLegend, 901513) was added to the remaining cleared lysate and incubated for 4 hours at $4{ }^{\circ} \mathrm{C}$ on an end-over-end rotator. Pierce ${ }^{\mathrm{TM}}$ Protein A/G Magnetic Beads were resuspended by gentle vortexing and transferred into DNA LoBind tubes. The tubes were placed on a magnetic stand and the storage buffer was discarded. $400 \mu \mathrm{L}$ of the homogenization buffer was added and the tubes were incubated for 5 minutes on an end-over-end rotator. The beads were collected with the magnetic stand and the buffer was discarded. The cleared lysate and with the antibody was added to the beads and incubated overnight at $4{ }^{\circ} \mathrm{C}$ in an end-over-end rotator. On the next day, the high-salt buffer was prepared freshly (50 mM Tris- $\mathrm{HCl}, \mathrm{pH}$ 7.5; 300 mM KCl; 12 mM MgCl2; 1\% Nonidet P-40 substitute; $0.5 \mathrm{mM} \mathrm{DTT} ; 100 \mu \mathrm{g} / \mathrm{mL}$ cycloheximide). The samples were placed into the magnetic stand and the supernatant removed. $800 \mu \mathrm{L}$ of high-salt buffer was added to tubes to remove nonspecific binding from the immunoprecipitates and the tubes were washed for 5 minutes on an end-over-end rotator at $4{ }^{\circ} \mathrm{C}$. The tubes were then placed into the magnetic stand and the supernatant removed. The high-salt washes were repeated twice more, for a total of three washes. In the last washing step, the 
beads were transferred to a clean tube, and all high-salt buffer was carefully removed. $350 \mu \mathrm{L}$ RLT buffer from the Qiagen RNeasy extraction kit supplemented with $\beta$-mercaptoethanol was added to the tubes, which were then vortexed for 30 seconds at room temperature. The tubes were placed into the magnetic stand, and total RNA was extracted from the immunoprecipitates following Qiagen's RNeasy extraction kit directions. Total RNA was quantified using Nanodrop and Qubit, and the integrity was assessed using the Tapestation.

\section{Purification of cardiomyocytes from total hearts}

The purification of cardiomyocytes from mouse hearts was done according to a protocol published by Acker-Johnson et al. [83]. Briefly, the mice were anaesthetized with isoflurane and the chest was opened to expose the heart. The descending aorta was cut and the heart was perfused through the right ventricle with $7 \mathrm{~mL}$ of EDTA buffer $\left(130 \mathrm{mM} \mathrm{NaCl}, 5 \mathrm{mM} \mathrm{KCl}, 0.5 \mathrm{mM} \mathrm{NaH}_{2} \mathrm{PO}_{4}, 10 \mathrm{mM}\right.$ HEPES, $10 \mathrm{mM}$ glucose, $10 \mathrm{mM}$ BDM, $10 \mathrm{mM}$ taurine, $5 \mathrm{mM}$ EDTA, pH adjusted to 7.8 with $\mathrm{NaOH}$ and sterile filtered). Ascending aorta was clamped using hemostatic forceps, and the heart was excised and submerged in fresh EDTA buffer in a $60 \mathrm{~mm}$ dish. The heart was then perfused through the left ventricle with $10 \mathrm{~mL}$ EDTA buffer, $3 \mathrm{~mL}$ perfusion buffer $\left(130 \mathrm{mM} \mathrm{NaCl}, 5 \mathrm{mM} \mathrm{KCl}, 0.5 \mathrm{mM} \mathrm{NaH}_{2} \mathrm{PO}_{4}\right.$, $10 \mathrm{mM}$ HEPES, $10 \mathrm{mM}$ glucose, $10 \mathrm{mM}$ BDM, $10 \mathrm{mM}$ taurine, $1 \mathrm{mM} \mathrm{MgCl}$, $\mathrm{pH}$ adjusted to 7.8 with $\mathrm{NaOH}$ and sterile filtered) and $30-50 \mathrm{~mL}$ of collagenase buffer $(0.5 \mathrm{mg} / \mathrm{mL}$ collagenase $2,0.5 \mathrm{mg} / \mathrm{mL}$ collagenase $4,0.05 \mathrm{mg} / \mathrm{mL}$ protease XIV in perfusion buffer, heated to $37^{\circ} \mathrm{C}$ ). Digested hearts were pulled apart into $1 \mathrm{~mm}$ pieces using forceps and gently triturated using a P1000 pipette. Digestion was stopped by adding stop buffer (perfusion buffer with $5 \%$ FBS), and the cell suspension was filtered through a $100 \mu \mathrm{m}$ strainer. The cells were submitted to two rounds of gravitational sedimentation of 15-20 minutes each, and then used for subsequent analyses.

\section{Preparation of cardiomyocyte ribosomes (for Mass Spectrometry analysis)}

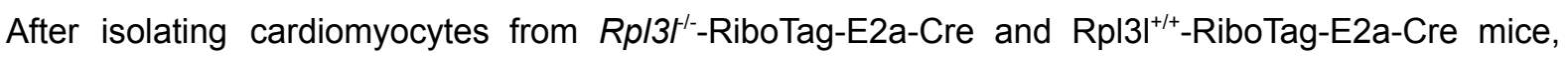
ribosomes were pulled down using anti-HA antibodies and magnetic beads, as explained above. Ribosomes bound to magnetic beads were washed three times using the high salt buffer, and then another six times with $200 \mathrm{mM}$ ammonium bicarbonate (ABC, \#09830-500G, Sigma, MI, US) to wash away the detergent. The beads were then resuspended in $6 \mathrm{M}$ urea (\#17-1319-01, GE Healthcare, UK) in $200 \mathrm{mM} \mathrm{ABC}$ and reduced by adding $10 \mathrm{mM}$ DTT (\#D9163-25G, Sigma, MI, US) in ABC (37 ${ }^{\circ} \mathrm{C}, 60$ minutes with shaking) and then alkylated in the dark with $20 \mathrm{mM}$ iodoacetamide (\#D9163-25G, Sigma, MI, US), (25 ${ }^{\circ} \mathrm{C}, 30 \mathrm{~min}$ ). On-bead digestion was performed using $0.2 \mu \mathrm{g} / \mu \mathrm{L}$ trypsin (Sequence-grade, \#V5111, Promega, WI, US) at $37{ }^{\circ} \mathrm{C}$, overnight with shaking. The beads were separated from the supernatant on a magnet, and the supernatant was acidified with $100 \%$ formic acid (\#1.00264.0100, Merck, DK). C18 stage tips (UltraMicroSpin Column, \#SUM SS18V, The Nest Group, Inc., MA, US) were then conditioned by adding methanol (\#14262, Sigma, MI, US) and centrifuged at $100 \mathrm{~g}$ for $5 \mathrm{~min}$. They were then equilibrated by two additions of $5 \%$ formic acid and 
centrifuged as in the previous step. Acidified samples were then loaded onto the columns and centrifuged at $100 \mathrm{~g}$ for $10 \mathrm{~min}$. The samples were reapplied and the centrifugation step repeated. Three washing steps were performed with $5 \%$ formic acid, and the peptides were eluted using $50 \%$ acetonitrile (\#34967, Sigma, MI, US) 5\% formic acid. The elute was vacuum dried and used for subsequent analyses.

\section{Digestion and analysis of cardiomyocyte protein samples using Mass Spectrometry}

Samples $(10 \mu \mathrm{g})$ were reduced with dithiothreitol $\left(100 \mathrm{mM}, 37^{\circ} \mathrm{C}, 60 \mathrm{~min}\right)$ and alkylated in the dark with iodoacetamide $\left(5 \mu \mathrm{mol}, 25^{\circ} \mathrm{C}, 20 \mathrm{~min}\right)$. The resulting protein extract was washed with $2 \mathrm{M}$ urea with $100 \mathrm{mM}$ TRIS-HCl and then with $50 \mathrm{mM}$ ammonium bicarbonate for digestion with endoproteinase LysC (1:10 w:w, 370 , o/n, Wako, cat \#129-02541) and then for trypsin digestion (1:10 w:w, $37^{\circ} \mathrm{C}, 8 \mathrm{~h}$, Promega cat \# V5113) following Wiśniewski et al. fasp procedure [84]. After digestion, peptide mix was acidified with formic acid and desalted with a MicroSpin C18 column (The Nest Group, Inc) prior to LC-MS/MS analysis. Samples were analyzed using a Orbitrap Eclipse mass spectrometer (Thermo Fisher Scientific, San Jose, CA, USA) coupled to an EASY-nLC 1200 (Thermo Fisher Scientific (Proxeon), Odense, Denmark). Peptides were loaded directly onto the analytical column and were separated by reversed-phase chromatography using a 50-cm column with an inner diameter of $75 \mu \mathrm{m}$, packed with $2 \mu \mathrm{m}$ C18 particles spectrometer (Thermo Scientific, San Jose, CA, USA). Chromatographic gradients started at $95 \%$ buffer $A$ and $5 \%$ buffer $B$ with a flow rate of 300 $\mathrm{nL} /$ minutes for 5 minutes and gradually increased to $25 \%$ buffer $B$ and $75 \% \mathrm{~A}$ in 79 minutes and then to $40 \%$ buffer $\mathrm{B}$ and $60 \% \mathrm{~A}$ in $11 \mathrm{~min}$. After each analysis, the column was washed for 10 minutes with $10 \%$ buffer $A$ and $90 \%$ buffer B. Buffer A: $0.1 \%$ formic acid in water. Buffer B: $0.1 \%$ formic acid in $80 \%$ acetonitrile.The mass spectrometer was operated in positive ionization mode with nanospray voltage set at $2.4 \mathrm{kV}$ and source temperature at $305^{\circ} \mathrm{C}$. The acquisition was performed in data-dependent acquisition (DDA) mode and full MS scans with 1 micro scans at resolution of 120,000 were used over a mass range of $\mathrm{m} / \mathrm{z}$ 350-1400 with detection in the Orbitrap mass analyzer. Auto gain control (AGC) was set to 'auto' and charge state filtering disqualifying singly charged peptides was activated. In each cycle of data-dependent acquisition analysis, following each survey scan, the most intense ions above a threshold ion count of 10000 were selected for fragmentation. The number of selected precursor ions for fragmentation was determined by the "Top Speed" acquisition algorithm and a dynamic exclusion of 60 seconds. Fragment ion spectra were produced via high-energy collision dissociation (HCD) at normalized collision energy of $28 \%$ and they were acquired in the ion trap mass analyzer. AGC was set to $2 \mathrm{E} 4$, and an isolation window of $0.7 \mathrm{~m} / \mathrm{z}$ and a maximum injection time of $12 \mathrm{~ms}$ were used. Digested bovine serum albumin (NEB, P8108S) was analyzed between each sample to avoid sample carry-over and to assure stability of the instrument and QCloud [85] has been used to control instrument longitudinal performance during the project. The MaxQuant software suite (v1.6.0.16) was used for peptide identification and quantification. The data were searched against a Swiss-Prot mouse database (as in June 2020, 17056 entries) plus Q9CQD0, 
E9PWZ3, Q3V1Z5 isoforms and a list of common contaminants and all the corresponding decoy entries [86]. A precursor ion mass tolerance of $4.5 \mathrm{ppm}$ at the MS1 level was used, and up to two missed cleavages for trypsin were allowed. The fragment ion mass tolerance was set to $0.5 \mathrm{Da}$. Oxidation of methionine, and protein acetylation at the $\mathrm{N}$-terminal were defined as variable modification; whereas carbamidomethylation on cysteines was set as a fixed modification. Identified peptides and dependent peptides have been filtered using a $5 \%$ and $1 \%$ FDR respectively. MaxLFQ [87] was used and fold change, p-value and q-value was calculated to compare WT vs KO. Due to similarity between RPL3 and RPL3L proteins, peptides identified "by matching" were discarded from the analysis. Indeed, we confirmed that most peptides with intensities for RPL3 in WT samples (FQTMEEK, IGQGYLIKDGK and VAFSVAR) were only identified 'By matching'. Skyline-daily software1 (v21.1.1.233) was used to extract the area of the peptides and to confirm that the intensity of the peptides were much less abundant or absent in WT compared to KO samples, thus most likely representing false positives. Skyline [88] library was generated with the msms.txt output of the MaxQuant search. Thus, all peptides assigned "by matching" were discarded from the analyses and final results. The raw proteomics data have been deposited to the PRIDE [89] repository with the dataset identifier PXD026985.

\section{PolyA(+) RNA selection from mouse hearts}

Poly(A) selection was performed using Dynabeads Oligo(dT)25 beads (Invitrogen, 61002) starting from either HA-pulldown immunoprecipitated RNA ( 5 to $10 \mu \mathrm{g}$ of input) or from total RNA from whole hearts ( $15 \mu \mathrm{g}$ of input). The beads were first pelleted on a magnetic stand and resuspended in binding buffer (20 mM Tris- $\mathrm{HCl}$, pH 7.5, 1.0 M LiCl, 2 mM EDTA). The beads were repelleted, the buffer was removed, and the beads were resuspended in binding buffer. Total RNA (5 to $10 \mu \mathrm{g}$ ) in DEPC-treated water was mixed 1:1 with binding buffer, and the mixture was immediately heated at $65{ }^{\circ} \mathrm{C}$ for 2 minutes. The mixture was then added to the beads, mixed thoroughly by pipetting and incubated on the end-over-end rotator for 10 minutes at room temperature. The samples were placed on the magnet and the supernatant was transferred to a clean tube (for the second round of the poly(A) selection). The beads were washed with washing buffer $B(10 \mathrm{mM}$ Tris- $\mathrm{HCl}, \mathrm{pH} 7.5 ; 0.15 \mathrm{M} \mathrm{LiCl} ; 1$ mM EDTA ; 10 mM Tris-HCl, pH 7.5) three times, and the supernatant was removed. The first round of poly(A)-containing RNA was eluted with cold $10 \mathrm{mM}$ Tris- $\mathrm{HCl}, \mathrm{pH} 7.5$ by heating the mixture at $75^{\circ} \mathrm{C}$ for 2 minutes. The supernatant for the second poly(A) selection was denatured by heating at $65^{\circ} \mathrm{C}$ for 3 minutes and immediately placed on ice. The beads were resuspended in lysis/binding buffer (100 mM Tris- $\mathrm{HCl}, \mathrm{pH}$ 7.5; 500 mM LiCl; 10 mM EDTA; 1\% LiDS; 5 mM DTT), placed on the magnet and the supernatant was removed. The denatured RNA was added to the beads, mixed thoroughly by pipetting and incubated on an end-over-end rotator for 10 minutes at room temperature. The tube was placed on the magnet and the supernatant was discarded. The washing steps and the elution were performed as previously described, and the elute was mixed with the elute from the first round. In the 
case of $\operatorname{poly}(A)$ selection from whole hearts, the two elutes were mixed with the beads for a third round.

\section{Nanopore direct cDNA sequencing library preparation}

All Nanopore sequencing runs were performed using the MinION sequencer (flow cell type: FLO-MIN106, sequencing kit: SQK-DCS109, barcoding expansion kit: EXP-NBD104). Standard Oxford Nanopore direct cDNA sequencing protocol (version DCB_9091_v109_revC_04Feb2019) was used to sequence mouse total RNA heart samples (input) as well as translated fractions (HA-bound). $100 \mathrm{ng}$ of Poly(A) selected RNA per sample was used for the first strand synthesis reaction, mixed with $2.5 \mu \mathrm{L}$ of VNP (ONT cDNA sequencing kit), $1 \mu \mathrm{L}$ of $10 \mathrm{mM}$ dNTPs and filled to $7.5 \mu \mathrm{L}$ with RNase-free water. The mixture was incubated at $65^{\circ} \mathrm{C}$ for 5 minutes and then snap cooled on ice. The following reagents were mixed in a separate tube: $4 \mu \mathrm{L}$ of $5 \mathrm{x}$ RT buffer, $1 \mu \mathrm{L}$ RNaseOUT (Invitrogen $^{\mathrm{TM}}$ ), $1 \mu \mathrm{L}$ of RNase-free water and $2 \mu \mathrm{L}$ of Strand-Switching Primer (SSP, ONT cDNA sequencing kit). The tubes were gently mixed by flicking and incubated at $65^{\circ} \mathrm{C}$ for 2 minutes. $1 \mu \mathrm{L}$ of Maxima H Minus Reverse Transcriptase (Life Technologies, EP0751) was added to the reaction mixture, which was mixed by flicking and incubated for 90 minutes at $42{ }^{\circ} \mathrm{C}$, followed by heat inactivation at $85^{\circ} \mathrm{C}$ for 5 minutes. RNA was degraded by adding $1 \mu \mathrm{L}$ of RNase Cocktail Enzyme Mix (ThermoFisher, AM2286) followed by incubation for 10 minutes at $37^{\circ} \mathrm{C}$. DNA cleanup was performed using AMPure XP beads and quantity and quality were assessed using Qubit ${ }^{\mathrm{TM}}$ and Tapestation ${ }^{\mathrm{TM}}$. The second strand was synthesized by mixing the following reagents: $25 \mu \mathrm{L}$ of $2 x$ LongAmp Taq Master Mix (NEB, 174M0287S), $2 \mu \mathrm{L}$ PR2 primer (ONT cDNA sequencing kit), $20 \mu \mathrm{L}$ reverse-transcribed sample and $3 \mu \mathrm{L}$ RNase-free water. The reaction mixture was incubated using the following protocol: $94{ }^{\circ} \mathrm{C}, 1$ minute; $50{ }^{\circ} \mathrm{C}, 1$ minute; $65{ }^{\circ} \mathrm{C}, 15$ minutes; $4{ }^{\circ} \mathrm{C}$, hold. Another AMPure $\mathrm{XP}$ beads cleanup step was performed, proceeding to the end-prep step by mixing the following reagents: $20 \mu \mathrm{L}$ cDNA sample, $30 \mu \mathrm{L}$ RNase-free water, $7 \mu \mathrm{L}$ Ultra II End-prep reaction buffer (NEB, E7647A), $3 \mu \mathrm{L}$ Ultra II End-prep enzyme mix (NEB, E76468). The mixture was incubated at $20^{\circ} \mathrm{C}$ for 5 minutes and $65{ }^{\circ} \mathrm{C}$ for 5 minutes. After another AMPure XP beads cleanup step, the samples were barcoded by mixing the following reagents: $22.5 \mu \mathrm{L}$ End-prepped cDNA, $2.5 \mu \mathrm{L}$ native barcode (NB01-NB12, ONT barcode extension kit EXP-NBD104), $25 \mu \mathrm{L}$ Blunt/TA ligase master mix. The reaction mixture was incubated for 10 minutes at room temperature, and the barcoded samples were cleaned up using AMPure XP beads. The cDNA amounts were measured using Qubit ${ }^{\mathrm{TM}}$, and the samples were pooled together in equal ratios, not exceeding $120 \mathrm{ng}(200 \mathrm{fmol})$ as the maximum total amount of barcoded cDNA. The adapter ligation was performed by mixing together $65 \mu \mathrm{L}$ of the pooled barcoded sample, $5 \mu \mathrm{L}$ Adapter Mix II (AMII, ONT cDNA sequencing kit), $20 \mu \mathrm{L}$ NEBNext Quick Ligation Reaction Buffer 5X (NEB, B6058S) and $10 \mu \mathrm{L}$ Quick T4 DNA Ligase (NEB, M2200L). The reaction mixture was incubated for 10 minutes at room temperature, after which the CDNA was cleaned up using AMPure XP beads and eluted in $13 \mu \mathrm{L}$ of Elution Buffer (EB, ONT cDNA sequencing kit). The final amount was $\sim 50 \mathrm{ng}$ of cDNA, which was mixed with $37.5 \mu \mathrm{L}$ Sequencing Buffer (SQB) 
and $2.5 \mu \mathrm{L}$ Loading Beads (LB, ONT cDNA sequencing kit) and loaded onto a previously primed MinION flowcell.

\section{Analysis of cDNA nanopore sequencing data (Nano-TRAP)}

Basecalling and demultiplexing of the raw fast5 files was done using Guppy (version 3.6.1) through the MasterOfPores pipeline (version 1.1) [90]. Fastq files were then mapped to the GRCm38 mouse genome, in which all non-protein coding sequences were previously masked. Mapping was performed using minimap2 (version 2.14) [91]. The bam files were used for the subsequent differential expression analysis, and Gencode's M25 mouse release was used as the annotation file. Differential expression analysis of nanopore cDNA sequencing runs (Nano-TRAP input and IP) was performed using bambu (version 0.3.0) (doi: 10.18129/B9.bioc.bambu, pre-publication release). DeltaTE (initial release) was used to compute the translation efficiency [92]. All code for analysis of Nano-TRAP data is available at : https://github.com/imilenkovic/RPL3L/tree/main/bambu and https://github.com/imilenkovic/RPL3L/tree/main/Nano-TRAP_TE.

\section{Ribosome profiling library preparation}

For heart homogenates, mice were sacrificed, and their hearts were quickly excised, washed in PBS containing $100 \mu \mathrm{g} / \mathrm{mL}$ cycloheximide (CHX), and snap frozen in liquid nitrogen. Left ventricular tissue was homogenized using a tissue homogenizer in 5 volumes of ice-cold polysome buffer ( $20 \mathrm{mM}$ Tris

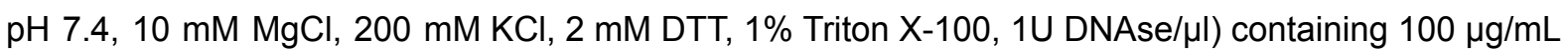
$\mathrm{CHX}$ and further homogenized using a $25 \mathrm{G}$ needle. For complete lysis, the samples were kept on ice for 10 minutes and subsequently centrifuged at $20,000 \mathrm{~g}$ to precipitate cell debris and the supernatant was immediately used in the further steps. From the lysate, $100 \mu \mathrm{L}$ was used as input, from which RNA was extracted using Trizol. The remaining lysate was used to generate RPFs by treatment with RNAse I for 45 minutes at room temperature. After 45 minutes the reaction was stopped by adding SUPERase RNAse Inhibitor. RPFs were purified using MicroSpin S-400 columns (Cytiva). Purified RPFs were used for the generation of Ribosome profiling libraries using the NEXTFLEX small-RNAseq V3 kit (Perkin-Elmer) according to the user guide. Input RNA libraries were prepared using NEBNext ${ }^{\circledR}$ Poly $(A)$ mRNA Magnetic Isolation Module (ref. e7490) and NEBNext $\circledast$ Ultra II Directional RNA Library Prep Kit for Illumina (24 reactions ref. e7760 or 96 reactions ref. e7765) according to the manufacturer's protocol, to convert total RNA into a library of template molecules of known strand origin and suitable for subsequent cluster generation and DNA sequencing. For all samples, ribosome profiling library size distributions were checked on the Bioanalyzer 2100 using a high sensitivity DNA assay (Agilent) and input libraries were analyzed using Bioanalyzer DNA 1000 or Fragment Analyzer Standard Sensitivity (ref: 5067-1504 or ref: DNF-473, Agilent) to estimate the quantity and validate the size distribution, and were then quantified by qPCR using the KAPA Library Quantification Kit KK4835 (REF. 07960204001, Roche) prior to the amplification with Illumina's cBot. Libraries were sequenced $1{ }^{*} 50+8$ bp on Illumina's HiSeq2500. 


\section{Ribosome profiling data analysis}

Fastq files were processed and analyzed using the RiboToolkit [93] and RiboFlow (initial release) followed by RiboR [94] pipelines. RiboToolkit was used to calculate the codon occupancy at A, E and P sites and the translation efficiency. Briefly, cutadapt (version 1.18) [95] was used to trim 5' and 3' adapters and to filter out low quality reads. Trimmed fastq files were uploaded to the RiboToolkit website and the analysis was done using default parameters. RiboFlow was used to process the fastq files (trimming, mapping, filtering reads mapping to rRNA and tRNA sequences, aligning to the transcriptome), and the created ribo objects were loaded to RiboR which was used to produce the 3-nt periodicity plots. Metagene plots were made using the $\mathrm{R}$ package ribosomeprofilingQC (https://bioconductor.org/packages/release/bioc/html/ribosomeProfilingQC.html).

\section{Single nuclei RNAseq library preparation}

Single nuclei were obtained from flash-frozen tissues that were dissociated following a previously described method [96]. Tissue homogenization was performed using a $7 \mathrm{~mL}$ glass Dounce tissue grinder set (Merck) with 8 strokes of a loose and a tight pestle in homogenization buffer $(250 \mathrm{mM}$ sucrose, $25 \mathrm{mM} \mathrm{KCl}, 5 \mathrm{mM} \mathrm{MgCl}$, $10 \mathrm{mM}$ Tris-HCl, $1 \mathrm{mM}$ dithiothreitol (DTT), 1X protease inhibitor, $0.4 \cup \mu L-1$ RNaseln, $0.2 \cup \mu L-1$ SUPERaseln, $0.1 \%$ Triton $\mathrm{X}-100$ in nuclease-free water). Homogenate was filtered into a $50 \mathrm{~mL}$ tube through a $40-\mu \mathrm{m}$ cell strainer (Corning) and centrifuged $\left(500 \mathrm{~g}, 5 \mathrm{~min}, 4^{\circ} \mathrm{C}\right)$ to resuspend the pellet in $500 \mu \mathrm{L}$ of storage buffer $(1 \times \mathrm{PBS}, 4 \%$ bovine serum albumin (BSA), $0.2 \cup \mu \mathrm{l}-1$ Protector RNaseln). Nuclei were stained with NucBlue Live ReadyProbes Reagents (ThermoFisher) and single nuclei were sorted by fluorescent activated cell sorting (FACS). The obtained tube was centrifuged $\left(500 \mathrm{~g}, 5 \mathrm{~min}, 4^{\circ} \mathrm{C}\right.$ ) to get nuclei pellet. Next, $5 \mu \mathrm{L}$ of single nuclei suspension were mixed with $5 \mu \mathrm{L}$ of Trypan Blue and applied to a Countess II to determine the nuclei concentration. The suspension was adjusted to $800-1,400$ cells per $\mu \mathrm{L}$ and loaded to the Chip, targeting the recovery of 5,000 nuclei per sample. The Chip was processed using the Chromium Controller protocol (10X Genomics). Libraries were prepared following the Chromium Single Cell 3' Reagent Kits User Guide (10X Genomics) protocol. Libraries were sequenced using NovaSeq 6000 flowcell (Illumina).

\section{Single nuclei RNAseq data analysis}

Sequenced single nuclei samples were demultiplexed using bcl2fastq (Illumina) and aligned to the annotated mouse reference genome (mm38, Ensembl v98) with CellRanger (v5.0.0) using default parameters and including introns to globally capture expression of pre-mRNA transcripts. Genomic regions corresponding to annotated ribosomal protein pseudogenes were masked out. Mapped samples were grouped into AnnData objects and analyzed by Scanpy v 1.6.0 [97]. Doublets were predicted and removed using Solo (score < 0.25) [98] and only nuclei with 300-5,000 expressed genes were retained. A gene was considered as expressed if at least one unique molecular identifier 
(UMI) was detected in 3 nuclei. Nuclei with less than 200 UMI or an abnormally high proportion of mitochondrial RNAs $(\geq 10 \%)$ or ribosomal RNAs $(\geq 40 \%)$, were further removed. Next, UMI were normalized so that every nuclei has the same total UMI count, and nuclei were clustered and visually displayed using the UMAP method [99]. Possible sample batches were corrected using Harmony [100]. We should note that snRNA-Seq captured RPL3L transcripts in nuclei from $R p / 3 /^{/-}$mice (Figure S3). However, the $13 \mathrm{bp}$-long deletion in $R p / 3 H^{--}$cells was confirmed, since no reads were found to span the CRISPR target sequence (Figure S3). RPL3L transcripts are not present in cytosolic extracts of $\mathrm{Rp} 3 \mathrm{H}^{-/}$hearts (Figure $2 \mathrm{~B}$ ), suggesting that they are readily degraded in the cytosol, most likely via nonsense-mediated decay (NMD) mechanisms. The jupyter notebook used for this analysis is available at: https://github.com/imilenkovic/RPL3L/tree/main/single_nuclei_analysis.

\section{Imputation of mRNA expression levels in sc-nucRNAs-seq}

We run MAGIC (v. 0.1.0) [101] to impute gene expression corrected for dropout and to recover ribosome paralog pair relationships. MAGIC was run using the table of single nuclei normalized UMI and with default parameters (number pca components $=20, k a=10, t=6$ ).

\section{Animal Ethics}

All experimental procedures were approved by the Garvan/St Vincent's Hospital Animal Ethics Committee, in accordance with the guidelines of the Australian Code of Practice for the Care and Use of Animals for Scientific Purposes (Project No. 16/14 and 16/26). All animals were entered into the study in a randomized order and operators were blinded to genotype and treatments.

\section{DATA AND CODE AVAILABILITY}

Nano-TRAP (IP and Input) and Ribo-Seq (RPF and mRNA) FASTQ files have been deposited in the Gene Expression Omnibus (GEO), under accession codes GSE189872 and GSE189854, respectively. Proteomics data has been deposited in PRIDE, under accession code PXD026985. A complete list of samples and corresponding codes can be found in Table S13.

All scripts used throughout this work, including those used to perform single cell data analysis, Nano-TRAP analyses, Ribo-Seq analyses, phylogenetic trees and heatmaps of RP expression patterns, have been made publicly available in GitHub (https://github.com/imilenkovic/RPL3L).

\section{ACKNOWLEDGEMENTS}

We thank all the members of the Novoa lab for their valuable insights and discussion. We thank Dr. Elisenda Sanz Iglesias for her invaluable insights regarding the RiboTag mice. We thank Dr. Rob Brink for all his help and discussions on diverse strategies to obtain the CRISPR knockout mice strains used in this work. We thank Prof. John McCarthy for providing us with an aliquot of the RPL3L antibody, as well as for insightful discussions on the role of RPL3L. We thank Prof. Dr. Antonio 
Zorzano and Dr. David Sebastián for the discussions and insights regarding mitochondrial biology. We thank Dr. Jorge Ferrer for providing us with a cre mouse line. We thank Ana Arsenijevic for her help with the PyMOL structures. IM is supported by "la Caixa" InPhINIT PhD fellowship (LCF/BQ/DI18/11660028). This project has received funding from the European Union's Horizon 2020 research and innovation programme under the Marie Skodowska-Curie grant agreement No. 713673. This work was supported by the Australian Research Council (DE170100506 to EMN) and the Spanish Ministry of Economy, Industry and Competitiveness (MEIC) (PGC2018-098152-A-100 to EMN). We acknowledge the support of the MEIC to the EMBL partnership, Centro de Excelencia Severo Ochoa and CERCA Programme / Generalitat de Catalunya. Proteomics analyses were performed in the CRG/UPF Proteomics Unit, which is part of the Proteored, PRB3 and is supported by grant PT17/0019, of the PE I+D+i 2013-2016, funded by ISCIII and ERDF.

\section{AUTHOR CONTRIBUTIONS}

IM performed most of the experiments and bioinformatic analyses described in this work, including mouse tissue collection and colony management, mice genotyping, cardiomyocyte preparations, total RNA and protein extractions, western blotting, immunofluorescence assays, polysome profiling, immunoprecipitation, nanopore sequencing, Nano-TRAP and RiboSeq data analyses. HGSV performed sucrose gradients, characterized RP antibodies across tissues, and contributed to the set up of mouse tissue polysome profiles. MCL contributed to mouse tissue collections and cardiomyocyte isolations. GP built the sc-nucRNA libraries, and JR performed the sc-nucRNAseq data analyses, which were supervised by $\mathrm{NH}$ and SvH. SK and JW performed echocardiography experiments, which were supervised by MF. GE and ES performed mass spectrometry experiments. MV built the Ribo-Seq libraries. EMN conceived and supervised the work. IM and EMN wrote the paper, with the contribution from all authors.

\section{DECLARATIONS OF INTERESTS}

EMN has received travel expenses to participate in Nanopore conferences. The authors declare that they have no competing interests.

\section{REFERENCES}

1. Genuth NR, Barna M. The Discovery of Ribosome Heterogeneity and Its Implications for Gene Regulation and Organismal Life. Mol Cell [Internet]. 2018;71:364-74. Available from: http://dx.doi.org/10.1016/j.molcel.2018.07.018

2. Kondrashov N, Pusic A, Stumpf CR, Shimizu K, Hsieh AC, Ishijima J, et al. Ribosome-mediated specificity in Hox mRNA translation and vertebrate tissue patterning. Cell [Internet]. 2011;145:383-97. Available from: $\mathrm{http}: / / \mathrm{dx}$.doi.org/10.1016/j.cell.2011.03.028

3. Komili S, Farny NG, Roth FP, Silver PA. Functional specificity among ribosomal proteins regulates gene expression. Cell [Internet]. 2007;131:557-71. Available from:

http://dx.doi.org/10.1016/j.cell.2007.08.037 
4. Crick FH. Biochemical activities of nucleic acids. The present position of the coding problem. Brookhaven Symp Biol [Internet]. 1959;12:35-9. Available from:

https://www.ncbi.nlm.nih.gov/pubmed/13812855

5. Mauro VP, Edelman GM. The ribosome filter hypothesis. Proc Natl Acad Sci U S A [Internet]. 2002;99:12031-6. Available from: http://dx.doi.org/10.1073/pnas.192442499

6. Shi Z, Fujii K, Kovary KM, Genuth NR, Röst HL, Teruel MN, et al. Heterogeneous Ribosomes Preferentially Translate Distinct Subpools of mRNAs Genome-wide. Mol Cell [Internet]. 2017;67:71-83.e7. Available from: http://dx.doi.org/10.1016/j.molcel.2017.05.021

7. Sugihara $\mathrm{Y}$, Honda $\mathrm{H}$, lida $\mathrm{T}$, Morinaga $\mathrm{T}$, Hino $\mathrm{S}$, Okajima T, et al. Proteomic analysis of rodent ribosomes revealed heterogeneity including ribosomal proteins L10-like, L22-like 1, and L39-like. J Proteome Res [Internet]. 2010;9:1351-66. Available from: http://dx.doi.org/10.1021/pr9008964

8. Slavov N, Semrau S, Airoldi E, Budnik B, van Oudenaarden A. Differential Stoichiometry among Core Ribosomal Proteins. Cell Rep [Internet]. 2015;13:865-73. Available from: http://dx.doi.org/10.1016/j.celrep.2015.09.056

9. Guimaraes JC, Zavolan M. Patterns of ribosomal protein expression specify normal and malignant human cells. Genome Biol [Internet]. 2016;17:236. Available from:

http://dx.doi.org/10.1186/s13059-016-1104-z

10. Ferretti MB, Karbstein K. Does functional specialization of ribosomes really exist? RNA [Internet]. 2019;25:521-38. Available from: http://dx.doi.org/10.1261/rna.069823.118

11. Gerst JE. Pimp My Ribosome: Ribosomal Protein Paralogs Specify Translational Control. Trends Genet [Internet]. 2018;34:832-45. Available from: http://dx.doi.org/10.1016/j.tig.2018.08.004

12. Gilbert WV. Functional specialization of ribosomes? Trends Biochem Sci [Internet]. 2011;36:127-32. Available from: http://dx.doi.org/10.1016/j.tibs.2010.12.002

13. Guo H. Specialized ribosomes and the control of translation. Biochem Soc Trans [Internet]. 2018;46:855-69. Available from: http://dx.doi.org/10.1042/BST20160426

14. Chaillou T, Zhang X, McCarthy JJ. Expression of Muscle-Specific Ribosomal Protein L3-Like Impairs Myotube Growth. J Cell Physiol [Internet]. 2016;231:1894-902. Available from: http://dx.doi.org/10.1002/jcp.25294

15. Khatter H, Myasnikov AG, Natchiar SK, Klaholz BP. Structure of the human 80 S ribosome. Nature [Internet]. 2015;520:640-5. Available from: http://dx.doi.org/10.1038/nature14427

16. Samir P, Browne CM, Rahul, Sun M, Shen B, Li W, et al. Identification of Changing Ribosome Protein Compositions using Mass Spectrometry. Proteomics [Internet]. 2018;18:e1800217. Available from: http://dx.doi.org/10.1002/pmic.201800217

17. Collins JC, Ghalei H, Doherty JR, Huang H, Culver RN, Karbstein K. Ribosome biogenesis factor Ltv1 chaperones the assembly of the small subunit head. J Cell Biol [Internet]. 2018;217:4141-54. Available from: http://dx.doi.org/10.1083/jcb.201804163

18. Loveland AB, Bah E, Madireddy R, Zhang Y, Brilot AF, Grigorieff N, et al. Ribosome $\cdot$ RelA structures reveal the mechanism of stringent response activation. Elife [Internet]. eLife Sciences Publications, Ltd; 2016;5:e17029. Available from: https://elifesciences.org/articles/17029

19. Dean EJ, Davis JC, Davis RW, Petrov DA. Pervasive and persistent redundancy among duplicated genes in yeast. PLoS Genet [Internet]. 2008;4:e1000113. Available from: http://dx.doi.org/10.1371/journal.pgen.1000113

20. Rotenberg MO, Moritz M, Woolford JL Jr. Depletion of Saccharomyces cerevisiae ribosomal protein L16 causes a decrease in $60 S$ ribosomal subunits and formation of half-mer polyribosomes. 
bioRxiv preprint doi: https://doi.org/10.1101/2021.12.04.471171; this version posted December 4,2021 . The copyright holder for this preprint (which was not certified by peer review) is the author/funder, who has granted bioRxiv a license to display the preprint in perpetuity. It is made available under aCC-BY-NC-ND 4.0 International license.

Genes Dev [Internet]. 1988;2:160-72. Available from: http://dx.doi.org/10.1101/gad.2.2.160

21. Gupta V, Warner JR. Ribosome-omics of the human ribosome. RNA [Internet]. 2014;20:1004-13. Available from: http://dx.doi.org/10.1261/rna.043653.113

22. Segev N, Gerst JE. Specialized ribosomes and specific ribosomal protein paralogs control translation of mitochondrial proteins. J Cell Biol [Internet]. 2018;217:117-26. Available from: http://dx.doi.org/10.1083/jcb.201706059

23. Xue S, Barna M. Specialized ribosomes: a new frontier in gene regulation and organismal biology. Nat Rev Mol Cell Biol [Internet]. 2012;13:355-69. Available from: http://dx.doi.org/10.1038/nrm3359

24. Burn TC, Connors TD, Van Raay TJ. Generation of a transcriptional map for a 700-kb region surrounding the polycystic kidney disease type 1 (PKD1) and tuberous sclerosis type 2 (TSC2) disease genes .... Genome [Internet]. genome.cshlp.org; 1996; Available from: https://genome.cshlp.org/content/6/6/525.short

25. Van Raay TJ, Connors TD, Klinger KW, Landes GM, Burn TC. A novel ribosomal protein L3-like gene (RPL3L) maps to the autosomal dominant polycystic kidney disease gene region. Genomics [Internet]. Elsevier; 1996;37:172-6. Available from: http://dx.doi.org/10.1006/geno.1996.0538

26. Thorolfsdottir RB, Sveinbjornsson G, Sulem P, Nielsen JB, Jonsson S, Halldorsson GH, et al. Coding variants in RPL3L and MYZAP increase risk of atrial fibrillation. Commun Biol [Internet]. 2018;1:68. Available from: http://dx.doi.org/10.1038/s42003-018-0068-9

27. Ganapathi M, Argyriou L, Martínez-Azorín F, Morlot S, Yigit G, Lee TM, et al. Bi-allelic missense disease-causing variants in RPL3L associate neonatal dilated cardiomyopathy with muscle-specific ribosome biogenesis. Hum Genet [Internet]. 2020;139:1443-54. Available from: http://dx.doi.org/10.1007/s00439-020-02188-6

28. Al-Hassnan ZN, Almesned A, Tulbah S, Alakhfash A, Alhadeq F, Alruwaili N, et al. Categorized Genetic Analysis in Childhood-Onset Cardiomyopathy. Circ Genom Precis Med [Internet]. 2020;13:504-14. Available from: http://dx.doi.org/10.1161/CIRCGEN.120.002969

29. Cardoso-Moreira M, Halbert J, Valloton D, Velten B, Chen C, Shao Y, et al. Gene expression across mammalian organ development. Nature [Internet]. 2019;571:505-9. Available from: http://dx.doi.org/10.1038/s41586-019-1338-5

30. Yokoyama T, Machida K, Iwasaki W, Shigeta T, Nishimoto M, Takahashi M, et al. HCV IRES Captures an Actively Translating 80S Ribosome. Mol Cell [Internet]. 2019;74:1205-14.e8. Available from: http://dx.doi.org/10.1016/j.molcel.2019.04.022

31. Pieper U, Webb BM, Dong GQ, Schneidman-Duhovny D, Fan H, Kim SJ, et al. ModBase, a database of annotated comparative protein structure models and associated resources. Nucleic Acids Res [Internet]. 2014;42:D336-46. Available from: http://dx.doi.org/10.1093/nar/gkt1144

32. Ren Z, Yu P, Li D, Li Z, Liao Y, Wang Y, et al. Single-Cell Reconstruction of Progression Trajectory Reveals Intervention Principles in Pathological Cardiac Hypertrophy. Circulation [Internet]. 2020;141:1704-19. Available from: http://dx.doi.org/10.1161/CIRCULATIONAHA.119.043053

33. Simsek D, Tiu GC, Flynn RA, Byeon GW, Leppek K, Xu AF, et al. The Mammalian Ribo-interactome Reveals Ribosome Functional Diversity and Heterogeneity. Cell [Internet]. 2017;169:1051-65.e18. Available from: http://dx.doi.org/10.1016/j.cell.2017.05.022

34. Rodríguez-Galán O, García-Gómez JJ, Rosado IV, Wei W, Méndez-Godoy A, Pillet B, et al. A functional connection between translation elongation and protein folding at the ribosome exit tunnel in Saccharomyces cerevisiae. Nucleic Acids Res [Internet]. 2021;49:206-20. Available from: http://dx.doi.org/10.1093/nar/gkaa1200

35. Reynoso MA, Juntawong P, Lancia M, Blanco FA, Bailey-Serres J, Zanetti ME. Translating 
Ribosome Affinity Purification (TRAP) followed by RNA sequencing technology (TRAP-SEQ) for quantitative assessment of plant translatomes. Methods Mol Biol [Internet]. 2015;1284:185-207. Available from: http://dx.doi.org/10.1007/978-1-4939-2444-8_9

36. Moulik M, Vatta M, Witt SH, Arola AM, Murphy RT, McKenna WJ, et al. ANKRD1, the gene encoding cardiac ankyrin repeat protein, is a novel dilated cardiomyopathy gene. J Am Coll Cardiol [Internet]. 2009;54:325-33. Available from: http://dx.doi.org/10.1016/j.jacc.2009.02.076

37. Crocini C, Arimura T, Reischmann S, Eder A, Braren I, Hansen A, et al. Impact of ANKRD1 mutations associated with hypertrophic cardiomyopathy on contraction parameters of engineered heart tissue. Basic Res Cardiol [Internet]. 2013;108:349. Available from: http://dx.doi.org/10.1007/s00395-013-0349-x

38. Ingolia NT, Ghaemmaghami S, Newman JRS, Weissman JS. Genome-wide analysis in vivo of translation with nucleotide resolution using ribosome profiling. Science [Internet]. 2009;324:218-23. Available from: http://dx.doi.org/10.1126/science.1168978

39. Lake BB, Codeluppi S, Yung YC, Gao D, Chun J, Kharchenko PV, et al. A comparative strategy for single-nucleus and single-cell transcriptomes confirms accuracy in predicted cell-type expression from nuclear RNA. Sci Rep [Internet]. 2017;7:6031. Available from:

http://dx.doi.org/10.1038/s41598-017-04426-w

40. Lacar B, Linker SB, Jaeger BN, Krishnaswami SR, Barron JJ, Kelder MJE, et al. Nuclear RNA-seq of single neurons reveals molecular signatures of activation. Nat Commun [Internet]. 2016;7:11022. Available from: http://dx.doi.org/10.1038/ncomms 11022

41. Litviňuková M, Talavera-López $C$, Maatz $H$, Reichart $D$, Worth $C L$, Lindberg EL, et al. Cells of the adult human heart. Nature [Internet]. 2020;588:466-72. Available from:

http://dx.doi.org/10.1038/s41586-020-2797-4

42. Bonnot T, Gillard M, Nagel D. A simple protocol for informative visualization of enriched gene ontology terms. Bio Protoc [Internet]. Bio-Protocol, LLC; 2019;9. Available from:

https://bio-protocol.org/e3429

43. Lesnik C, Cohen Y, Atir-Lande A, Schuldiner M, Arava Y. OM14 is a mitochondrial receptor for cytosolic ribosomes that supports co-translational import into mitochondria. Nat Commun [Internet]. 2014;5:5711. Available from: http://dx.doi.org/10.1038/ncomms6711

44. Gold VAM, Chroscicki P, Bragoszewski P, Chacinska A. Visualization of cytosolic ribosomes on the surface of mitochondria by electron cryo-tomography. EMBO Rep [Internet]. EMBO;

2017;18:1786-800. Available from: https://onlinelibrary.wiley.com/doi/10.15252/embr.201744261

45. MacKenzie JA, Payne RM. Ribosomes specifically bind to mammalian mitochondria via protease-sensitive proteins on the outer membrane. J Biol Chem [Internet]. 2004;279:9803-10. Available from: http://dx.doi.org/10.1074/jbc.M307167200

46. Kearse MG, Ireland JA, Prem SM, Chen AS, Ware VC. RpL22e, but not RpL22e-like-PA, is SUMOylated and localizes to the nucleoplasm of Drosophila meiotic spermatocytes. Nucleus [Internet]. 2013;4:241-58. Available from: http://dx.doi.org/10.4161/nucl.25261

47. Lamoliatte F, Bonneil E, Durette C, Caron-Lizotte O, Wildemann D, Zerweck J, et al. Targeted identification of SUMOylation sites in human proteins using affinity enrichment and paralog-specific reporter ions. Mol Cell Proteomics [Internet]. 2013;12:2536-50. Available from:

http://dx.doi.org/10.1074/mcp.M112.025569

48. Frey N, Katus HA, Olson EN, Hill JA. Hypertrophy of the heart: a new therapeutic target? Circulation [Internet]. 2004;109:1580-9. Available from: http://dx.doi.org/10.1161/01.CIR.0000120390.68287.BB

49. Katz AM. Cardiomyopathy of overload. A major determinant of prognosis in congestive heart 
bioRxiv preprint doi: https://doi.org/10.1101/2021.12.04.471171; this version posted December 4,2021 . The copyright holder for this preprint (which was not certified by peer review) is the author/funder, who has granted bioRxiv a license to display the preprint in perpetuity. It is made available under aCC-BY-NC-ND 4.0 International license.

failure. N Engl J Med [Internet]. 1990;322:100-10. Available from: http://dx.doi.org/10.1056/NEJM199001113220206

50. Frey N, Olson EN. Cardiac hypertrophy: the good, the bad, and the ugly. Annu Rev Physiol [Internet]. 2003;65:45-79. Available from: http://dx.doi.org/10.1146/annurev.physiol.65.092101.142243

51. Wang Y, Zhang Y, Ding G, May HI, Xu J, Gillette TG, et al. Temporal dynamics of cardiac hypertrophic growth in response to pressure overload. Am J Physiol Heart Circ Physiol [Internet]. 2017;313:H1119-29. Available from: http://dx.doi.org/10.1152/ajpheart.00284.2017

52. Ma H, Yu S, Liu X, Zhang Y, Fakadej T, Liu Z, et al. Lin28a Regulates Pathological Cardiac Hypertrophic Growth Through Pck2-Mediated Enhancement of Anabolic Synthesis. Circulation [Internet]. 2019;139:1725-40. Available from:

http://dx.doi.org/10.1161/CIRCULATIONAHA.118.037803

53. Filipovska A, Rackham O. Specialization from synthesis: how ribosome diversity can customize protein function. FEBS Lett [Internet]. 2013;587:1189-97. Available from:

http://dx.doi.org/10.1016/j.febslet.2013.02.032

54. Ghulam MM, Catala M, Abou Elela S. Differential expression of duplicated ribosomal protein genes modifies ribosome composition in response to stress. Nucleic Acids Res [Internet]. 2020;48:1954-68. Available from: http://dx.doi.org/10.1093/nar/gkz1183

55. Petibon C, Malik Ghulam M, Catala M, Abou Elela S. Regulation of ribosomal protein genes: An ordered anarchy. Wiley Interdiscip Rev RNA [Internet]. 2021;12:e1632. Available from: http://dx.doi.org/10.1002/wrna.1632

56. Ferretti MB, Ghalei H, Ward EA, Potts EL, Karbstein K. Rps26 directs mRNA-specific translation by recognition of Kozak sequence elements. Nat Struct Mol Biol [Internet]. 2017;24:700-7. Available from: http://dx.doi.org/10.1038/nsmb.3442

57. Locati MD, Pagano JFB, Girard G, Ensink WA, van Olst M, van Leeuwen S, et al. Expression of distinct maternal and somatic 5.8S, 18S, and 28S rRNA types during zebrafish development. RNA [Internet]. 2017;23:1188-99. Available from: http://dx.doi.org/10.1261/rna.061515.117

58. Rogers MJ, Gutell RR, Damberger SH, Li J, McConkey GA, Waters AP, et al. Structural features of the large subunit rRNA expressed in Plasmodium falciparum sporozoites that distinguish it from the asexually expressed subunit rRNA. RNA [Internet]. 1996;2:134-45. Available from: https://www.ncbi.nlm.nih.gov/pubmed/8601280

59. Vembar SS, Droll D, Scherf A. Translational regulation in blood stages of the malaria parasite Plasmodium spp.: systems-wide studies pave the way. Wiley Interdiscip Rev RNA [Internet].

2016;7:772-92. Available from: http://dx.doi.org/10.1002/wrna.1365

60. Wong QW-L, Li J, Ng SR, Lim SG, Yang H, Vardy LA. RPL39L is an example of a recently evolved ribosomal protein paralog that shows highly specific tissue expression patterns and is upregulated in ESCs and HCC tumors. RNA Biol [Internet]. 2014;11:33-41. Available from: http://dx.doi.org/10.4161/rna.27427

61. Jiang L, Li T, Zhang X, Zhang B, Yu C, Li Y, et al. RPL10L Is Required for Male Meiotic Division by Compensating for RPL10 during Meiotic Sex Chromosome Inactivation in Mice. Curr Biol [Internet]. 2017;27:1498-505.e6. Available from: http://dx.doi.org/10.1016/j.cub.2017.04.017

62. Narla A, Ebert BL. Ribosomopathies: human disorders of ribosome dysfunction. Blood [Internet]. 2010;115:3196-205. Available from: http://dx.doi.org/10.1182/blood-2009-10-178129

63. O'Leary MN, Schreiber KH, Zhang Y, Duc A-CE, Rao S, Hale JS, et al. The ribosomal protein Rpl22 controls ribosome composition by directly repressing expression of its own paralog, Rpl22l1. PLoS Genet [Internet]. 2013;9:e1003708. Available from: 
bioRxiv preprint doi: https://doi.org/10.1101/2021.12.04.471171; this version posted December 4,2021 . The copyright holder for this preprint (which was not certified by peer review) is the author/funder, who has granted bioRxiv a license to display the preprint in perpetuity. It is made available under aCC-BY-NC-ND 4.0 International license.

http://dx.doi.org/10.1371/journal.pgen.1003708

64. Xiao Z, Zou Q, Liu Y, Yang X. Genome-wide assessment of differential translations with ribosome profiling data. Nat Commun [Internet]. 2016;7:11194. Available from:

http://dx.doi.org/10.1038/ncomms11194

65. Pagliara V, Saide A, Mitidieri E, d'Emmanuele di Villa Bianca R, Sorrentino R, Russo G, et al. 5 -FU targets rpL3 to induce mitochondrial apoptosis via cystathionine- $\beta$-synthase in colon cancer cells lacking p53. Oncotarget [Internet]. 2016;7:50333-48. Available from:

http://dx.doi.org/10.18632/oncotarget.10385

66. Kao BR, Malerba A, Lu-Nguyen NB, Harish P, McCarthy JJ, Dickson G, et al. Knockdown of Muscle-Specific Ribosomal Protein L3-Like Enhances Muscle Function in Healthy and Dystrophic Mice. Nucleic Acid Ther [Internet]. 2021; Available from: http://dx.doi.org/10.1089/nat.2020.0928

67. Zhou X, Lowdon RF, Li D, Lawson HA, Madden PAF, Costello JF, et al. Exploring long-range genome interactions using the WashU Epigenome Browser. Nat Methods [Internet]. 2013;10:375-6. Available from: http://dx.doi.org/10.1038/nmeth.2440

68. Gabunilas J, Chanfreau G. Splicing-Mediated Autoregulation Modulates Rpl22p Expression in Saccharomyces cerevisiae. PLoS Genet [Internet]. 2016;12:e1005999. Available from: http://dx.doi.org/10.1371/journal.pgen.1005999

69. Meskauskas A, Petrov AN, Dinman JD. Identification of functionally important amino acids of ribosomal protein L3 by saturation mutagenesis. Mol Cell Biol [Internet]. 2005;25:10863-74. Available from: http://dx.doi.org/10.1128/MCB.25.24.10863-10874.2005

70. Al-Hadid Q, Roy K, Chanfreau G, Clarke SG. Methylation of yeast ribosomal protein Rpl3 promotes translational elongation fidelity. RNA [Internet]. 2016;22:489-98. Available from: http://dx.doi.org/10.1261//rna.054569.115

71. Yang $\mathrm{H}$, Wang $\mathrm{H}$, Jaenisch R. Generating genetically modified mice using CRISPR/Cas-mediated genome engineering. Nat Protoc [Internet]. 2014;9:1956-68. Available from:

http://dx.doi.org/10.1038/nprot.2014.134

72. Qin W, Dion SL, Kutny PM, Zhang Y, Cheng AW, Jillette NL, et al. Efficient CRISPR/Cas9-Mediated Genome Editing in Mice by Zygote Electroporation of Nuclease. Genetics [Internet]. 2015;200:423-30. Available from: http://dx.doi.org/10.1534/genetics.115.176594

73. Sanz E, Yang L, Su T, Morris DR, McKnight GS, Amieux PS. Cell-type-specific isolation of ribosome-associated mRNA from complex tissues. Proc Natl Acad Sci U S A [Internet]. 2009;106:13939-44. Available from: http://dx.doi.org/10.1073/pnas.0907143106

74. Nishikawa K, Yoshida M, Kusuhara M, Ishigami N, Isoda K, Miyazaki K, et al. Left ventricular hypertrophy in mice with a cardiac-specific overexpression of interleukin-1. Am J Physiol Heart Circ Physiol [Internet]. 2006;291:H176-83. Available from: http://dx.doi.org/10.1152/ajpheart.00269.2005

75. Quiros PM, Goyal A, Jha P, Auwerx J. Analysis of mtDNA/nDNA Ratio in Mice. Curr Protoc Mouse Biol [Internet]. 2017;7:47-54. Available from: http://dx.doi.org/10.1002/cpmo.21

76. Begik O, Lucas MC, Liu H, Ramirez JM, Mattick JS, Novoa EM. Integrative analyses of the RNA modification machinery reveal tissue- and cancer-specific signatures. Genome Biol [Internet]. 2020;21:97. Available from: http://dx.doi.org/10.1186/s13059-020-02009-z

77. Mistry J, Chuguransky S, Williams L, Qureshi M, Salazar GA, Sonnhammer ELL, et al. Pfam: The protein families database in 2021 [Internet]. Nucleic Acids Research. 2020. Available from: http://dx.doi.org/10.1093/nar/gkaa913

78. Eddy S. HMMER: profile HMMs for protein sequence analysis. 1998.

79. Nguyen L-T, Schmidt HA, von Haeseler A, Minh BQ. IQ-TREE: a fast and effective stochastic 
algorithm for estimating maximum-likelihood phylogenies. Mol Biol Evol [Internet]. 2015;32:268-74. Available from: http://dx.doi.org/10.1093/molbev/msu300

80. Minh BQ, Schmidt H, Chernomor O, Schrempf D, Woodhams M, von Haeseler A, et al. IQ-TREE 2: New models and efficient methods for phylogenetic inference in the genomic era [Internet]. Available from: http://dx.doi.org/10.1101/849372

81. Rambaut A. FigTree v1. 4. 2012.

82. Sanz E, Bean JC, Carey DP, Quintana A, McKnight GS. RiboTag: Ribosomal Tagging Strategy to Analyze Cell-Type-Specific mRNA Expression In Vivo. Curr Protoc Neurosci [Internet]. 2019;88:e77. Available from: http://dx.doi.org/10.1002/cpns.77

83. Ackers-Johnson M, Li PY, Holmes AP, O’Brien S-M, Pavlovic D, Foo RS. A Simplified, Langendorff-Free Method for Concomitant Isolation of Viable Cardiac Myocytes and Nonmyocytes From the Adult Mouse Heart. Circ Res [Internet]. Am Heart Assoc; 2016;119:909-20. Available from: http://dx.doi.org/10.1161/CIRCRESAHA.116.309202

84. Wiśniewski JR, Zougman A, Nagaraj N, Mann M. Universal sample preparation method for proteome analysis. Nat Methods [Internet]. 2009;6:359-62. Available from:

http://dx.doi.org/10.1038/nmeth.1322

85. Chiva C, Olivella R, Borràs E, Espadas G, Pastor O, Solé A, et al. QCloud: A cloud-based quality control system for mass spectrometry-based proteomics laboratories. PLoS One [Internet]. 2018;13:e0189209. Available from: http://dx.doi.org/10.1371/journal.pone.0189209

86. Beer LA, Liu P, Ky B, Barnhart KT, Speicher DW. Efficient Quantitative Comparisons of Plasma Proteomes Using Label-Free Analysis with MaxQuant. Methods Mol Biol [Internet]. 2017;1619:339-52. Available from: http://dx.doi.org/10.1007/978-1-4939-7057-5_23

87. Cox J, Hein MY, Luber CA, Paron I, Nagaraj N, Mann M. Accurate proteome-wide label-free quantification by delayed normalization and maximal peptide ratio extraction, termed MaxLFQ. Mol Cell Proteomics [Internet]. 2014;13:2513-26. Available from:

http://dx.doi.org/10.1074/mcp.M113.031591

88. MacLean B, Tomazela DM, Shulman N, Chambers M, Finney GL, Frewen B, et al. Skyline: an open source document editor for creating and analyzing targeted proteomics experiments. Bioinformatics [Internet]. 2010;26:966-8. Available from: http://dx.doi.org/10.1093/bioinformatics/btq054

89. Vizcaíno JA, Csordas A, Del-Toro N, Dianes JA, Griss J, Lavidas I, et al. 2016 update of the PRIDE database and its related tools. Nucleic Acids Res [Internet]. 2016;44:11033. Available from: http://dx.doi.org/10.1093/nar/gkw880

90. Cozzuto L, Liu H, Pryszcz LP, Pulido TH, Delgado-Tejedor A, Ponomarenko J, et al. MasterOfPores: A Workflow for the Analysis of Oxford Nanopore Direct RNA Sequencing Datasets. Front Genet [Internet]. 2020;11:211. Available from: http://dx.doi.org/10.3389/fgene.2020.00211

91. Li H. Minimap2: pairwise alignment for nucleotide sequences. Bioinformatics [Internet]. 2018;34:3094-100. Available from: http://dx.doi.org/10.1093/bioinformatics/bty191

92. Chothani S, Adami E, Ouyang JF, Viswanathan S, Hubner N, Cook SA, et al. deltaTE: Detection of Translationally Regulated Genes by Integrative Analysis of Ribo-seq and RNA-seq Data. Curr Protoc Mol Biol [Internet]. 2019;129:e108. Available from: http://dx.doi.org/10.1002/cpmb.108

93. Liu Q, Shvarts T, Sliz P, Gregory RI. RiboToolkit: an integrated platform for analysis and annotation of ribosome profiling data to decode mRNA translation at codon resolution. Nucleic Acids Res [Internet]. 2020;48:W218-29. Available from: http://dx.doi.org/10.1093/nar/gkaa395

94. Ozadam H, Geng M, Cenik C. RiboFlow, RiboR and RiboPy: an ecosystem for analyzing 
bioRxiv preprint doi: https://doi.org/10.1101/2021.12.04.471171; this version posted December 4,2021 . The copyright holder for this preprint (which was not certified by peer review) is the author/funder, who has granted bioRxiv a license to display the preprint in perpetuity. It is made available under aCC-BY-NC-ND 4.0 International license.

ribosome profiling data at read length resolution. Bioinformatics [Internet]. 2020;36:2929-31. Available from: http://dx.doi.org/10.1093/bioinformatics/btaa028

95. Martin M. Cutadapt removes adapter sequences from high-throughput sequencing reads. EMBnet.journal [Internet]. 2011 [cited 2020 Jul 23];17:10-2. Available from: http://journal.embnet.org/index.php/embnetjournal/article/view/200

96. Litvinukova M, Lindberg E, Maatz $\mathrm{H}$, Zhang $\mathrm{H}$, Radke $\mathrm{M}$, Gotthardt $\mathrm{M}$, et al. Single cell and single nuclei analysis human heart tissue v1 [Internet]. protocols.io. ZappyLab, Inc.; 2018. Available from: https://www.protocols.io/view/single-cell-and-single-nuclei-analysis-human-heart-veae3ae

97. Wolf FA, Angerer P, Theis FJ. SCANPY: large-scale single-cell gene expression data analysis. Genome Biol [Internet]. 2018;19:15. Available from: http://dx.doi.org/10.1186/s13059-017-1382-0

98. Bernstein NJ, Fong NL, Lam I, Roy MA, Hendrickson DG, Kelley DR. Solo: Doublet Identification in Single-Cell RNA-Seq via Semi-Supervised Deep Learning. Cell Syst [Internet]. 2020;11:95-101.e5. Available from: http://dx.doi.org/10.1016/j.cels.2020.05.010

99. McInnes L, Healy J, Saul N, Großberger L. UMAP: Uniform Manifold Approximation and Projection [Internet]. Journal of Open Source Software. 2018. p. 861. Available from: http://dx.doi.org/10.21105/joss.00861

100. Korsunsky I, Millard N, Fan J, Slowikowski K, Zhang F, Wei K, et al. Fast, sensitive and accurate integration of single-cell data with Harmony. Nat Methods [Internet]. 2019;16:1289-96. Available from: http://dx.doi.org/10.1038/s41592-019-0619-0

101. van Dijk D, Sharma R, Nainys J, Yim K, Kathail P, Carr AJ, et al. Recovering Gene Interactions from Single-Cell Data Using Data Diffusion. Cell [Internet]. 2018;174:716-29.e27. Available from: http://dx.doi.org/10.1016/j.cell.2018.05.061 